\title{
Trans-tornando las memorias posibles del género. Juegos y choques con el sistema sexo/género*
}

\author{
Trans-Torning the Possible Gender's Memories. \\ Games and Clashes with the Sex/Gender System
}

\author{
Ian Anabel Arias Cuéllar** \\ Universidad Icesi, Colombia
}

DOI: $10.22380 / 2539472 X .855$

\begin{abstract}
RESUMEN
A través de un ejercicio de rememoración de dos personas que transgreden el género que les fue socialmente asignado (mujer), un hombre trans y una persona trans no binaria, retomo elementos de sus trayectorias para evidenciar, en diálogo con mi experiencia, la articulación entre memorias e identidad como puentes entre un pasado, un presente y un futuro en ruptura simbólica y social permanente. Hacer inteligibles estas experiencias íntimas, que desde la perspectiva de la matriz cultural del género son incoherentes, contribuye a la comprensión que tenemos de lo trans, del funcionamiento del género y sus memorias asociadas.
\end{abstract}

Palabras claves: transgénero, no binario, memoria, género.

\begin{abstract}
Through a remembrance exercise of two people who transgress the gender that was socially assigned to them (woman). A trans man and a nonbinary trans person, I take back elements of their trajectories to demostrate, in dialogue with my experience, the articulation between memories and identity. As bridges between a past, a present and a future in permanent, symbolic and social rupture. Making inteligible these intimate experiences, which from the perspective of cultural matrix of gender are presented as inconsistent, contributes to our understanding of the trans, to the functioning of gender and to its associated memories.
\end{abstract}

Keywords: transgender, non-binary, memory, gender.

* $\quad$ Este artículo es resultado de la investigación de la Maestría en Estudios Sociales y Políticos en la Universidad Icesi, financiada por el Centro de Estudios Afrodiaspóricos (CEAF) a través de una beca. Agradezco especialmente a Dan y Martín por sus contribuciones a mi proceso personal y académico, a Lina Buchely y a Esteban Restrepo por sus aportes a este texto, así como a los lectores durante el proceso editorial. Esta obra está bajo licencia internacional Creative Commons Reconocimiento-NoComercial-SinObrasDerivadas 4.0

** Sociólogo de la Universidad del Valle y magíster en Estudios Sociales y Políticos de la Universidad Icesi, Cali. transkatoarias@gmail.com / http://orcid.org/0000-0002-1798-9965 


\section{Introducción}

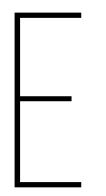

$n$ contextos de acontecimientos traumáticos y violentos, las memorias suelen ser pensadas como una posibilidad de enunciación de las vivencias de sectores invisibilizados que se reivindican como relevantes para una reconstrucción más plural y colectiva de las historias nacionales. Si bien la intensificación de los discursos de la memoria a partir de la década de 1970 se ha dinamizado por procesos de incidencia mundial que exponen su dimensión global, "el ámbito político de las prácticas de la memoria sigue siendo nacional, no posnacional o global” (Huyssen 2002, 220-221). La recuperación de la memoria de grupos minoritarios y/u oprimidos apenas toca a las personas trans y sus redes de sentido. Como lo explica Camilo Losada (2016) en su trabajo sobre la memoria de hombres transgénero, "las personas trans hemos estado por fuera de la historia, incluso por fuera de la memoria reconstruida por sectores populares, urbanos y rurales" (51).

Como un aporte a la política de las memorias trans, en este artículo reflexiono sobre las prácticas de memoria desde un ámbito atípico para estos discursos: la memoria personal en torno a la vivencia del propio género, la sexualidad y la corporalidad a partir de un género y una sexualidad no normativos. Analizo los relatos de dos personas que transitan entre los géneros sobre su desprendimiento de la categoría "mujer" -impuesta en razón de una determinada genitalidad-, sobre un pasado que permite hacer inteligible su autoimagen presente; para ello, me sitúo en la potente articulación entre memoria e identidad (Gillis 1994; Riaño-Alcalá 2006). Esto permite hablar de cómo las transformaciones íntimas, vividas en los niveles de la expresión de género y su relación con el cuerpo, constituyen un ámbito de ejercicio político de la identidad a través de una memoria que busca darles sentido, así como un proceso social de resignificación de categorías cada vez más visibles, como la de transgeneridad.

\section{Estudios trans y memoria}

Mientras que la investigación sobre la cuestión trans en Colombia se ha centrado principalmente en las identidades transfemeninas, desde perspectivas etnográficas y procesos políticos de reivindicación de derechos (Posso y La Furcia 2016, 180), la producción académica enfocada en las experiencias trans de personas 
que fueron asignadas mujer ${ }^{1}$, en supuesta coherencia con sus genitales, es notablemente escasa, tanto que solo ha sido posible rastrear dos trabajos académicos: el de Ana María Ortiz (2014), con un enfoque etnográfico y autoetnográfico de la experiencia y la identificación trans, y el de Losada (2016), realizado desde una perspectiva de memoria colectiva y de derechos humanos de un colectivo de hombres trans. Ambos desarrollos dialogan con los hallazgos de este artículo, que adopta un enfoque de memoria detenido en la experiencia personal del tránsito, abordando desde los relatos la conexión con fenómenos más amplios que disputan, hacen posibles o imposibles y luchadas las memorias trans.

Los efectos del régimen heteronormativo y cisgénero ${ }^{2}$ hacen particularmente intensa (y muchas veces angustiosa) la experiencia trans, producto de la violencia simbólica y epistémica sistemática, pues la transgresión del género asignado "no existe como lugar de enunciación posible” sino como "objeto de señalamiento, acoso, burla, sanción y expulsión” (Losada 2016, 25), y también de incertidumbre frente a la potencial violencia directa, especialmente, contra personas transfemeninas, de sectores populares y racializadas (CIDH 2015; CNMH 2015, 2018; Colombia Diversa, Caribe Afirmativo y Santamaría Fundación 2015).

Con este artículo propongo pensar las memorias en una escala diferente: las memorias personales sobre la trayectoria de vida y del tránsito entre los géneros de dos jóvenes transgénero, para descubrir el campo de batalla interno en el que se libran delicadas disputas por la autoimagen, la noción de la identidad trans, del género y la masculinidad, y se viven las sutiles o intensas presiones de ese régimen que sustenta el continuum de violencias que azota a la población LGTB en nuestra sociedad (CNMH 2015, 429). Para la experiencia íntima de lo trans, la memoria se convierte en una herramienta y en una disputa que se debate entre la visibilidad y el borramiento de aquello que evidencia lo trans en la narrativa de sí, en la propia consciencia, así como en la corporalidad y presentación ante $\mathrm{l}^{*} \mathrm{~s}^{3}$ demás (Stone [1992] 2015).

1 Con esta expresión me refiero a la atribución de una serie de parámetros, significados, normas y expectativas sociales sobre lo femenino y el ser mujer, adjudicadas a los seres con sexo "femenino" incluso antes de nacer.

2 Trans significa cambio, atravesar o a través de y más allá, del género asignado (Kessler y MacKenna 1978, en Ortiz 2014, 4). Por otro lado, "cisexual/cisgénero: del latín cis (de este lado) y sexus (sexo, entendido como identidad sexual) / generis (estirpe, linaje, nacimiento) define a las personas que se identifican con la asignación de sexo/género que recibieron al nacer" (Serano 2007). Vergueiro y Ramírez (2014, en Posso y La Furcia 2016, 178-179) comparan la cisgeneridad con la heterosexualidad o la blanquitud, dentro de los sistemas de opresión, en una operación que busca nominar la mayoría ideológica desmarcada gracias a su ascendencia hegemónica. 
Poner en el centro nuestras propias historias a través de la reelaboración de nuestras memorias, complejizando esos referentes discursivos, significa escuchar voces que han sido pormenorizadas en la explicación del fenómeno trans, en la descripción de nuestros sentires y formas de ser.

Este artículo consta de seis secciones. Después de esta introducción, en “¿Memorias imposibles?”, desarrollo el marco analítico que permite relacionar la memoria con el género y la transgeneridad. En la sección "Apuntes metodológicos” abordo los supuestos y alcances del presente ejercicio, algunos detalles acerca del proceso y la relación establecida con $1^{*}$ s entrevistad*s. A continuación, presento sus memorias en diálogo con las mías para un análisis que se plasma en tres partes: “Jugar con el género”, “Quiso esa imagen de una princesa” y "Existe un nombre para esto”. Las “Consideraciones finales” recogen las principales reflexiones del artículo.

\section{¿Memorias imposibles?}

La conceptualización de Ana Lucía Ramírez (2015) que articula género y memoria nos ayuda a pensar de qué manera los referentes colectivos de la memoria personal, que permiten seleccionar u olvidar aquellas vivencias pasadas significativas en nuestra experiencia del género, hacen o no posibles unas memorias específicas. Ramírez (2015, 90-92) argumenta que el género funciona también como un marco social de memoria colectiva para dos grupos dicotómicos: hombres y mujeres. Este marco engloba todas las facetas de la vida social y subjetiva de las personas, dado que "los conceptos de género estructuran la percepción y la organización, concreta y simbólica, de toda la vida social” (Scott 1996, 292-293) ${ }^{4}$. Tal conceptualización se conecta con la mirada de Assmann y Czaplicka (1995), quienes consideran que la memoria colectiva -importante noción de Halbwachs ([1968] 2004) — proporciona conocimientos caracterizados por "distinciones agudas entre los que pertenecen y los que no, es decir, entre lo que pertenece a uno mismo y lo que es extranjero" (130, traducción propia).

Cabral (2009); Galofre y Missé (2015a, 22), para un ejemplo de traducción en esa clave, y los comentarios editoriales de Espinosa en Saldivia (2017, 9), para conocer los argumentos e implicaciones en el proceso editorial del uso de la $x$.

4 Véase Scott, para ampliar la caracterización de las dimensiones sobre cómo opera la estructura binaria de género en tanto "elemento constitutivo de las relaciones sociales basadas en las diferencias que distinguen los sexos", compuesto por símbolos y representaciones culturales; parámetros normativos sobre su interpretación; "nociones políticas" e institucionales y "la identidad subjetiva" (289-291). 
Lo que da sentido a este marco social, al género como dispositivo institucional, es la matriz cultural heterosexual (Butler 2016, 71-72), la objetivación de un entramado discursivo en la cultura occidental que afirma una relación continua entre una determinada genitalidad (dos tipos de cuerpos desde el modelo del dimorfismo sexual), un género (supuesto efecto del cuerpo sexuado: solo dos géneros desde el modelo binario hombre-pene/mujer-vagina) y una orientación sexual (heterosexual). Lo anterior permite comprender y cuestionar la forma en que se ha entendido lo trans, problematizando las normas, los imaginarios y las prácticas institucionalizadas que fijan los contenidos de dos polos opuestos y coherentes: hombre/mujer, masculino/femenino, heterosexual/homosexual (García 2009, 125-128), y que ordenan transversalmente la experiencia íntima y pública del cuerpo, la identidad y el deseo en los ámbitos económicos, culturales y políticos. Podríamos decir que esta matriz es la memoria cultural del género, en tanto

[...] un grupo basa su conciencia de unidad y especificidad en este conocimiento y deriva de él impulsos formativos y normativos que le permiten al grupo reproducir su identidad. En este sentido, la cultura objetivada tiene la estructura de la memoria. (Assmann y Czaplicka 1995, 128)

La construcción del recuerdo individual, a través de un grupo que asume tener una imagen común de su pasado ${ }^{5}$, nos indica que la adscripción a uno de los dos géneros es la que nos permite saber “qué recuerdos, qué tipo de relatos y sentidos del pasado en torno al género y sus relaciones con el presente y las proyecciones de futuro serán inteligibles y cuáles no” (Ramírez 2015, 91). Por ello, las memorias de personas que no encajan en estas formas de identidad grupal se tornan memorias imposibles (Ricoeur 2007, 10) y situadas en el límite de lo decible (Ramírez 2015). Dada la ininteligibilidad social de sus memorias y experiencias, condensada como vergüenza o silencio, se lucha con la represión, las resistencias y las repeticiones. A esas personas las habita también el duelo, en un paradójico vaivén entre la pérdida efectiva que implica el deseo de cambio social y corporal, y el imperativo social de tener que "perder” o cambiar algo para acoplarse a los parámetros institucionalizados del género.

Esta imposibilidad de una memoria para las experiencias consideradas como “incongruentes" por la matriz heterosexual ha sido reproducida y garantizada por una serie de instituciones basadas en los postulados de la sexología de mediados del siglo XX (Balzer 2010, 83-85), así como en la lógica y el

5 En este caso, mediado por estructuras narrativas comunes que estabilizan las memorias y la identidad de género como "continuas en el tiempo, sin sobresaltos ni fisuras" (Ramírez 2015, 91). 
establecimiento médico-jurídico de la psiquiatría (Saldivia 2017; Stone [1992] 2015), que logró constituir primero el diagnóstico de la transexualidad que se globaliza y luego abarcó un mayor espectro de la transgeneridad como trastorno de identidad sexual (TIS), durante los años noventa ${ }^{6}$ (Balzer 2010; Benjamin [1966] 1999; Martínez-Guzmán y Montenegro 2009). A finales de los ochenta y durante los noventa, algunas pensadoras feministas y personas trans estadounidenses iniciaron el desarrollo de un corpus crítico sobre lo trans, sin negar las narrativas autobiográficas previas, pero afirmando un nuevo impulso para discutir la legitimidad de las “opiniones expertas” (Stryker 2015, 13). Desde diversas disciplinas y activismos en varios países, se buscó despatologizar ${ }^{7}$ y replantear los modelos que, desde la psicología y la psiquiatría, consideraron las variantes sexuales y de género como fenómenos anormales. En esa línea, adopto en este trabajo la premisa "de que ser trans no implica tener un desorden mental o médico” (Wittle 2006, XII) y asumo formas alternativas de definir lo trans.

Las categorías de transformista, travesti, transgénero y transexual han variado en sus usos y significados. Durante un largo periodo se ha pretendido establecer el dominio de una presumible identidad fija para cada una de ellas, sustentada en la dicotomía travesti/transexual (TV/TS) instaurada por Benjamin ([1966] 1999) y "basada, a su vez, en la dicotomía esencialista hombre-mujer del discurso heteronormativo” (Balzer 2010, 84). Sin embargo, algunos estudios empíricos en contextos latinoamericanos como Río de Janeiro y Bogotá han mostrado que las fronteras entre estas diversas categorías de autodenominación son bastante difusas y no guardan una relación necesaria ni unilateral con un tipo de prácticas sociales y corporales exclusivas para cada lugar/experiencia identitaria (Balzer 2010, 90-91; Ortiz 2014, 4). El reconocimiento de la complejidad y el dinamismo de las identidades trans, junto con la consolidación de una perspectiva política crítica (Feinberg 2015; Stryker 2006), ha favorecido la utilización de la categoría trans (en inglés transgender) como un término paraguas con el cual englobar todas las posibles expresiones de género que transgreden el binarismo

6 La Organización Mundial de la Salud (OMS) ha propuesto para la nueva versión de la Clasificación Internacional de Enfermedades (CIE 11) ubicar a las personas trans dentro del capítulo 17, "Condiciones relacionadas con la salud sexual", como diagnóstico de "incongruencia de género". Si bien continúa como condición patologizada, no implicará per se enfermedad, como sucede en la actual sección de "trastornos mentales y del comportamiento". De ser aprobada por la Asamblea Mundial de la Salud, la CIE 11 entraría en vigencia a partir de mayo del 2022 (Liberarte 2018). Para profundizar en los términos del trastorno de identidad sexual (TIS) en el Manual diagnóstico y estadístico de trastornos mentales del 2005 (DSM-IV), véase Martínez-Guzmán y Montenegro (2009, 11).

7 Para ampliar sobre el activismo y debate en torno a la despatologización trans, véase Missé y Coll-Planas (2010) y para el proceso de globalización de los estándares patologizantes, véase Balzer (2010). 
del sistema sexo/género y que pueden o no incluir intervenciones corporales más permanentes (Ramírez 2015, 1). Esa transgresión se concreta en la apropiación de elementos del género leído socialmente como opuesto - prácticas transgénero específicas (Halberstam 2008a, 10) - y es denominada en algunos casos como tránsito. Pero transgénero no es solo una identidad, sino un entramado de visiones y teorías del mundo, del cuerpo, de formas de vida, prácticas individuales y colectivas (Cabral [2006] 2011), y un término que recoge

[...] una amplia gama de fenómenos que llaman la atención sobre el hecho de que el género, como es vivido, encarnado, experimentado, performado y encontrado, es más complejo y variado que lo que puede ser explicado por la ideología binaria de sexo/género de la modernidad eurocéntrica actualmente dominante. (Stryker 2006, 3)

En particular, la creciente visibilidad de subjetividades transgénero/transexuales masculinas $\left(\mathrm{FTM}^{8}\right)$, en las últimas décadas a nivel global y en los últimos años a nivel regional, muestra una serie de transformaciones en el ámbito de la variación de género y de las identidades/experiencias de sexualidades no heteronormativas de cuerpos socialmente configurados como de "mujeres". Estas subjetividades cuestionan y reafirman, según el caso, los parámetros de la masculinidad presentes en los contextos locales, nacionales, globales/virtuales, en interacción ambivalente con la continuidad que la matriz cultural heterosexual busca mantener entre el sexo, el género y la sexualidad (Butler 2016, 72).

En este sentido, Halberstam (2008a, 24-25) considera como una aproximación reveladora lo que las masculinidades que no se ubican en el cuerpo de los “hombres” cisgénero nos pueden decir acerca del funcionamiento del género y de los modelos de masculinidad — hegemónicos y marginales-que están en juego en nuestras redes de socialización. Las transmasculinidades y las masculinidades femeninas ponen en evidencia las imaginerías y los mecanismos sociales, de encarnación, performáticos y simbólicos por los que estos modelos se configuran o se desacreditan. Descubren de una manera flagrante el carácter no esencial del efecto de masculinidad - las masculinidades como fantasías que desestructuran los binarios de género presentes en sus contextos sociales (La Furcia 2016)—.

Además de reflexionar sobre cómo se constituye simbólica y sociológicamente la masculinidad con las trayectorias focalizadas, en este artículo me interesa introducir el debate en torno a las continuidades y los trastrocamientos entre las experiencias de masculinidad de hombres trans ("tránsitos binarios”), por un lado, y de personas transgénero masculinizadas que se enuncian 
en disrupción con las exigencias de la dicotomía binaria del género, llamad*s cada vez más comúnmente "no binari*s" y/o transmasculin*s, por otro. Si bien hay experiencias de tránsitos binarios que se diferencian profundamente de las de personas transgénero masculinas no binarias, a nivel corporal, de expresión e identidad, también es cierto que las fronteras para trazar las diferencias se suelen traslapar. Es difícil sostener que los hombres trans o las transmasculinidades no binari*s son homogéne*s; incluso, ni siquiera quienes se enuncian como transexuales lo son, según las exploraciones de Halberstam (2008b), en el contexto estadounidense, o de Balzer (2010), en el caso de las transfemeninas en Brasil. Tanto sus trabajos como el de Stone ([1992] 2015) muestran también la dificultad de los estereotipos médicos para describir la experiencia real del cuerpo, el deseo y la identidad de las personas trans. Además de aportar a esta perspectiva, me interesa contribuir en el empeño de, adaptando una intención de Halberstam (2008b), crear un "espacio teórico y cultural" para las transgeneridades masculinas que no nos enunciamos como hombres, que no parta de "la transexualidad como su marco epistemológico”, así como a la comprensión de "la posibilidad de la persona transgénero no operada" (170).

Las subjetividades presentadas aquí cuestionamos varios de estos estereotipos y nos reconocemos en las diferencias que marcan fronteras, descubriendo simultáneamente que la línea que nos separa en otros aspectos es delgada, pero mucho menos rígida de lo que se suele pensar. A pesar de los diferentes lugares de enunciación, encarnación y experiencia, tenemos preocupaciones en común. Se trata de abordar las preguntas en torno a las "teorías de [la] encarnación sexuada y del desarrollo subjetivo de la identidad de género" y de analizar "las condiciones materiales [así] como de las prácticas de representación” prestando "especial atención a la interfaz entre las dos” (Stryker 2006, 3).

En este sentido, para no sucumbir, las memorias trans requieren cuestionar el conocimiento y las tensiones introducidas por el modelo patologizante entre las disidencias de sexo/género (Halberstam 2008b, 165-199) desde la interpretación crítica de la experiencia cotidiana. En esa sintonía, es de gran importancia analítica el correlato del género como dinámica cotidiana de relacionamiento informal, es decir, como memoria comunicativa (Assmann y Czaplicka 1995, 126), que intenta establecer unos parámetros y requerimientos sociales cotidianos de interacción, en concordancia con la matriz cultural de género, y produce la autopercepción más íntima de la persona, frente a lo cual las personas trans, en tanto existencias señaladas como "incongruentes", desplegamos diversas estrategias de disrupción y resistencia. Como he señalado arriba, una de las más importantes es la de nuestras memorias personales y de las redes y colectividades trans/queer, a 
las que aquí denomino memorias no hegemónicas, en tensión con la matriz cultural de género, heterosexual y cisnormativa, caracterizada como régimen político, económico e ideológico (Butler 2016; Wittig 1992).

Por lo anterior, las experiencias trans y sus memorias marginales son centrales, en tanto prácticas culturales y sistema de acción política desde donde se interpelan los parámetros de una memoria institucionalizada y normativa del género (Aguilar 2008; Calveiro 2012). De este modo, apunto a la revaloración de las interpretaciones que las personas trans hacen de sus prácticas y su realidad cotidiana como una forma legítima de dar sentido, y como un elemento sin el cual las explicaciones sobre las vidas trans están incompletas.

\section{Los trucos de la memoria personal y sus condiciones de producción: apuntes metodológicos}

El artículo parte de la consideración, común en la actualidad, de que las memorias no solo son plurales sino que están en pugna (Calveiro 2012; CNMH 2013, 13-16; Sánchez 2016). Esta afirmación, habitual en el estudio de las memorias colectivas sobre procesos y acontecimientos nacionales, es válida también para las experiencias personales que analizo. Esto, al menos en dos sentidos: por un lado, son plurales — cambiantes, superpuestas y muchas veces contradictoriasa lo largo de nuestra existencia, y por otro, se vinculan con "marcos interpretativos” más amplios y también plurales (Goffman [1974] 2006; Suess 2010, 30). Estos marcos, igualmente en tensión, circulan en campos y organizaciones sociales (grupos, medios de comunicación e instituciones) y permiten constituir el sentido que atribuimos a las circunstancias, eventos, decisiones y acciones en nuestra vida individual y colectiva, y por tanto a su memoria.

La interpretación de nuestro pasado personal dialoga con múltiples marcos interpretativos en una relación simbiótica con la autopercepción individual (Gillis 1994). Pero ni la identidad ni la memoria son objetos fijos o estáticos, sino artefactos sociales que reactualizamos constantemente (Gillis 1994; Hall 2010). Los relatos de las memorias son una construcción funcional a una manera específica y temporalmente situada de percibirse y proyectarse. Como sostiene Gillis (1994), el "sentido de igualdad a través del tiempo y del espacio" (3), que implica la construcción de identidad individual (o grupal), "es mantenido por el recuerdo; y lo que es recordado está definido por la identidad asumida” (3). 
En sintonía con lo anterior, los relatos que analizo y con los que dialogo son considerados ejercicios subjetivos de narración en los que hay un esfuerzo de mis compañer*s y mío por integrar una heterogeneidad de componentes discontinuos y discordantes de la existencia (Ricoeur [1989] 2006), esa "mezcla de acción y sufrimiento, actuar y padecer, que constituye la trama misma de una vida” (50), teniendo en cuenta que organizar la vida en un orden lógico, cronológico y "según relaciones inteligibles" (Bourdieu 1989, 75) es una labor del sujeto convertido "en el ideólogo de la propia vida, seleccionando, en función de un propósito global, unos acontecimientos significativos concretos y estableciendo entre ellos unas conexiones que sirvan para justificar su existencia y darle coherencia” (76). Es por esto que el sentido y la temporalidad de los relatos de nuestras memorias personales son siempre ambiguos.

Los relatos analizados aquí no se toman entonces como la prueba de unos hechos constatados por ellos como “testimonio". En tanto artefactos sociales y culturales, tienen una fuerza por sí mismos para, por un lado, hablarnos de las operaciones que desplegamos en la configuración y comprensión de nuestras subjetividades trans, y por otro, brindarnos elementos (conexiones sugeridas en -y por- los relatos) para comprender su vínculo significativo con campos, redes sociales y relaciones de poder que estructuran los contextos más allá del relato, los cuales dejan marcas en la configuración específica de nuestras memorias. Esos procesos sociales que permiten constituir nuestras subjetividades son simultáneos, superpuestos, relacionados de múltiples maneras, incluso si en los relatos algunos se presentan en una sucesión. Por ello, solo aproximándose críticamente a las memorias y a sus “'pecados' normales” (Winter 2008, 12), estas permiten hablar de las relaciones y condiciones sociales que ayudan a seleccionarlas de una manera dada, puesto que "la memoria nos juega trucos y esos trucos son muy reveladores” (10).

Lo anterior implica una dimensión reflexiva que toca a quien investiga, dado que la comprensión crítica debe aplicarse también sobre mi propia mirada, tomando consciencia de las herramientas conceptuales y metodológicas puestas en juego en el oficio sociológico y del tipo de vínculo que establezco con mis compañer*s -en una simbiosis entre una mirada insider, como parte, en tanto trans y amig*; y outsider, desde la perspectiva de los códigos disciplinares (Ghasarian 2008, 15)—. Todo esto incide en el desarrollo del trabajo de campo, que se intersecta inevitablemente con la amistad en una dimensión emocional, en el intercambio casual, en las entrevistas y en el panorama de situaciones, reflexiones, sentimientos, imaginarios y prácticas que fui captando para comprender las experiencias de mis compañer*s y las mías. Implica el examen crítico de mis 
propias memorias e identidad de género y sexual, reconfiguradas en estas relaciones de intercambio.

Mi lugar de enunciación en esta investigación se ha configurado en tanto sociólog* trans, inconforme del género, que ha iniciado consciente, y cada vez más públicamente, un tránsito simultáneo al proceso investigativo, un privilegio distante de la realidad de muchas personas trans. Esta relación tránsito-investigación va en dos vías. Por un lado, la experiencia puede contribuir a una apuesta etnográfica y sociológica, así como a mi crecimiento como cientista social, asumiendo que, como decía Bourdieu (2002): “no hay nada más falso que la máxima [...] de que el* investigador* no debe poner nada de sí mism* en su investigación [...] debería referirse constantemente a sus experiencias, pero no de manera culposa, inconsciente o incontrolada” (95; asteriscos añadidos). En este sentido, si bien el artículo se centra en las experiencias de mis dos compañer*s, también está atravesado por mi experiencia personal que emerge y se entreteje, en algunas partes, con el escrito.

Por otro lado, esta indagación académica ha secundado decisiones ligadas a la inconformidad frente a algunos aspectos de mi corporalidad y a la certeza afianzada durante años de no sentirme acorde con la categoría mujer, a través de una sociología encarnada (Wacquant 2006, 26-27) en la que encarno a un mí mism* que va rearmándose en un proceso de conocimiento y familiarización con algo que me era extraño y a la vez no. Para realizar la investigación contacté personas de mis círculos sociales con quienes parecíamos compartir algunas dimensiones de esta experiencia, buscando acercarme a sus comprensiones y sentires e identificar relaciones, similitudes y diferencias.

Busqué incluir mi cercanía personal al tema como un elemento que enriquece la perspectiva de conocimiento situado (Haraway [1988] 1995; Harding 2003), asumida como ejercicio de reflexividad en la investigación y en el resultado escrito (Ghasarian 2008) ${ }^{9}$. En esa medida, este trabajo se fundamenta en una aproximación que prioriza una perspectiva parcial como alternativa a los sesgos positivista y relativista (Haraway 1988, 328-329), lo cual implica un vínculo inherente entre el lugar social, el cuerpo y la experiencia desde donde se construyen los conocimientos teóricos y, por supuesto, desde donde se elaboran los datos empíricos. No solo la selección del tema, sino la manera de aproximación íntima a las personas y sus relatos, y el estilo de escritura en primera persona parten

9 "La consideración de los hechos subjetivos favorece, en lugar de aniquilar, la objetividad del trabajo. Cada vez más los antropólogos consideran que, más que evitar negar o buscar controlar (distanciamiento) los elementos personales y las emociones en juego en el campo, es necesario comprenderlos e integrarlos en la investigación (Kleinman y Copp 1993, en Ghasarian 2008, 16). 
de una implicación personal, que se asume desde la elaboración reflexiva de la experiencia (Collins 1998, 278, 283), dirigida a contribuir a los debates en torno a las memorias y concepciones de los procesos de tránsito. Con esta postura epistemológica, me aparto de denominaciones como "informantes" o "sujetos de investigación” - u otras maneras propias de las ciencias sociales-, y para referirme a las personas que aportaron sus relatos y reflexiones utilizo la expresión "mis compañer*s"10, ya que la expresión resalta el vínculo común de experiencia en tanto personas trans - sin ocultar las diferencias internas-. También lo hago como una manera de evidenciar que, más que sujetos analizables, sus reflexiones son formas de problematización y comprensión situada de la realidad.

Así, este trabajo es una construcción atravesada, por un lado, por los relatos de dos de mis compañer*s, que me han acompañado como interlocutor*s informad*s desde sus propias experiencias e investigaciones autodidactas, realizadas en función de sus tránsitos. Por otro lado, por las experiencias y conocimientos mutuos que hemos alcanzado en nuestras interacciones, así como en mis experiencias del tránsito. Es también un esfuerzo por profundizar algo que he ido observando y experimentando: la incorporación de prácticas transgénero demanda recurrentes y específicos ejercicios de reflexividad sobre cómo funciona el género en relación con el cuerpo, la sexualidad, los entornos e instituciones en los que te mueves, y en las relaciones sociales e interacciones que estableces con otras personas. Esto es muy significativo, dado que la memoria es un elemento reflexivo del tránsito y la reflexividad requiere de una memoria crítica.

\section{Los rostros del tránsito, las técnicas y los ejes abordados}

Dan y Martín fueron asignad*s como "mujeres", pero se han desprendido de esta categoría y presentan una expresión de género codificada socialmente y reivindicada como masculina. Dan se asume como una persona en un tránsito no binario y Martín como hombre trans. Amb*s han decidido intervenir su cuerpo mediante una terapia de reemplazo hormonal, una de sus prácticas transgénero.

Dan nació en Bogotá y fue criado desde los seis años en Villavicencio, luego volvió a la Universidad Nacional de Colombia, donde se graduó en el 2013, tras 
realizar su investigación en el Pacífico. Ha trabajado en intervención comunitaria y educación popular en Cali, así como en un bar los fines de semana. Luego ingresó a una organización defensora de derechos humanos, principalmente, de mujeres trans. A finales de noviembre del 2017 se radicó en São Paulo. Actualmente tiene veintiocho años, se considera una persona fenotípicamente mestiza y percibida de esa manera en los contextos colombianos en los que ha vivido. Cambió su nombre en la cédula, pero no busca cambiar la $F$ en la casilla "sexo". Su familia - padres, tí*s y herman*s - se ha mostrado abierta a intentar comprender el proceso de tránsito de Dan, "lo respetan pero no sé si lo están asumiendo como un tránsito” (Dan, audio de WhatsApp, 20 de noviembre del 2018).

A Dan $1^{*}$ conocía desde hace años sin tener un vínculo cercano. Justo antes de iniciar mi maestría se mudó al apartaestudio debajo de mi casa y a finales del 2017 convivimos en mi casa dos meses antes de que viajara. Construimos una relación de intercambio en torno a nuestra experiencia del género, que se intensificó a mediados del 2017 cuando me propuso empezar a tomar testosterona junt*s. Esto sucedió en agosto, iniciando una etapa de cambios y fuertes reflexiones compartidas. Durante esa época identifiqué que teníamos maneras distintas de asumir los cambios corporales y la relación con la mirada de l*s otr*s, a pesar de que compartíamos la idea de no querer ser o sentirnos como "hombres". Estas diferencias, así como el permanente intercambio en el marco de nuestra amistad, han sido fundamentales para una comprensión reflexiva de mi propia experiencia, en la medida en que hemos podido entrever las transformaciones sociales y personales que vivimos, las múltiples contradicciones emocionales, discursivas y prácticas que emergen en estos tránsitos.

Martín nació en Cali, tiene veintiséis años, es una persona percibida fenotípicamente como blanca y es diseñador gráfico. En los primeros semestres de la carrera conoció a su pareja (2013), una mujer cisgénero con la que se casó en el 2017. En el 2014 inició abiertamente su proceso de tránsito y su reemplazo hormonal. Hacia el 2015 se independizó de sus padres, debido a los conflictos desatados con su madre por su decisión de transitar. Su padre aceptó y ha apoyado su tránsito, y su hermano, un poco menor, parece tener una posición ambivalente. Ha trabajado en varias agencias en donde muy pocas personas saben que es trans; aunque cambió su nombre, no quiere cambiar la $F$ en la casilla "sexo" de la cédula. No ha vivido fuera de Cali, donde reside actualmente con su esposa en un barrio de clase media.

A Martín lo conocí en un encuentro realizado en Bogotá el 2017, organizado por Dan y otras personas para hablar de lo sucedido en una Escuela Transfeminista. Allí pudimos hablar entre personas trans de nuestras experiencias. Volví a encontrarlo en marzo del 2018 en una actividad de grupos LGBT en el centro de 
la ciudad; le comenté sobre mi proceso personal y de investigación y se mostró interesado en apoyarme en los dos aspectos. Realizamos una entrevista y empezamos a vernos constantemente para hablar de manera informal durante varias semanas. Nuestra relación ha devenido en una amistad en la que compartimos momentos de esparcimiento, intercambiamos historias cotidianas derivadas de ser trans y asuntos personales. Con Martín también he identificado cercanías, especialmente en la manera en la que nos vemos en retrospectiva (como niños masculinos), y compartimos la situación de haber sido reprendid*s por pretender a una niña a muy temprana edad —en mi caso, por una persona externa a mi familia-. A la vez, hay una gran distancia en la manera de autodenominarnos; él es un hombre, yo, una persona trans (sin más).

Por mi parte nací en Cali, tengo treinta años, soy una persona percibida como fenotípicamente blanca y me gradué de Sociología en la Universidad del Valle. Mi madre es educadora de ciencias naturales y mi padre, electricista del Servicio Nacional de Aprendizaje (SENA); ambos se desempeñaron como emplead*s públic*s, lo que les permitió incorporarse a la clase media. Desde el 2009 vengo cuestionándome el género que se me exige socialmente, lo cual relaciono con la cercanía que tuvimos - junto con mi pareja de la época- a una mujer trans. En el 2015 empecé a considerar la necesidad de intervenir quirúrgicamente mis senos. Hacia el 2017 usé testosterona por un corto periodo, lo que me permitió tomar la decisión de reducir mis senos a inicios del 2018, todo en el marco de esta investigación. Tanto la toma de hormonas como la cirugía implican cambios corporales que sigo abiert* a retomar. Mi madre, mi padre y mi hermano me han apoyado en el proceso. No quiero cambiar la $F$ en la casilla "sexo" de la cédula, pero sí proyecto incorporar mi nuevo nombre elegido (Ian), junto al asignado por mis padres (Anabel).

Con Dan hice dos entrevistas y con Martín, una. Fueron ejercicios de rememoración de las vivencias que consideran significativas sobre la manera en que han experimentado su género, su cuerpo y su sexualidad en el marco del tránsito entre los géneros, así como sobre los momentos claves para devenir en tránsito y las nociones que tienen de este. También tuvimos múltiples conversaciones personales informales en contextos de intercambio amistoso y por WhatsApp formulé preguntas adicionales para complementar las entrevistas.

Con este material elaboré un documento sobre cada trayectoria de tránsito. De cada una seleccioné fragmentos de las temáticas tratadas y otros aspectos emergentes, que agrupé de la siguiente manera: 1) la percepción sobre el propio género: conciencias de inadecuación y rupturas con el género asignado; 2) la percepción sobre el propio cuerpo: inconformidad y resistencias; 3) el acceso 
a información sobre las experiencias trans a través de redes, colectivos e instituciones sociales, y 4) temporalidades y relación con los pasados, presentes y futuros: lógicas/prácticas del recuerdo y el olvido ${ }^{11}$. Los ejes se entretejen a lo largo de la presentación de las memorias de Dan y Martín, sin seguir el estricto orden anterior, y con el análisis del* investigador*, en un ejercicio intersubjetivo y social que sigue reactualizando nuestras memorias.

\section{Jugar con el género: la historia de una ruptura en dominó}

La forma en que Dan recuerda el proceso de transformación del género asignado se remonta a sus veinte años, a partir de varios hitos significativos que surgen con preguntas en torno al placer sexual, que explora inicialmente a través de vínculos heterosexuales y que pronto se tornan lésbicos:

Fue cuando me hice preguntas sobre mi vida sexual [...] ni en la adolescencia ni en la niñez tuve cosas, así como de relaciones [...] [las] amistades que habían sido más fuertes siempre habían sido con chicas y como que nunca me había pensado por qué no me gustaban ellas, fue como la pregunta que me llevó a relacionarme con mujeres. (Dan, entrevista, 10 de septiembre del 2017)

Transcurría el año 2011. Dan se encontraba en sexto semestre cuando empezó a centrar todos sus trabajos académicos en la experiencia de la sexualidad y el género de un cuerpo que, como el suyo, desafiaba los parámetros de la heterosexualidad obligatoria con su placer corporal. El primero de estos ejercicios fue fotográfico y consistía en deconstruir el cuerpo femenino: "ser mujer, ¿qué significa? Y no hay un solo modelo de feminidad, por ahí empezó la cosa [...] y con el tema de, en ese momento, ser lesbiana, como que empezaron a caerse muchas cosas, o conceptos que tenía sobre mí o sobre la vida” (Dan, entrevista, 10 de septiembre del 2017, énfasis añadido). En el medio, decide cambiar su nombre de chica por uno neutro, acción que no se vinculó todavía con un desprendimiento consciente del género asignado ni con la noción de tránsito, sino con el gusto y el

11 Tres niveles analíticos propuestos por Tilly (2001) para el análisis de procesos históricos complejos han sido útiles en la interpretación de los procesos y elementos en los relatos de mis compañer*s, estos son: el contextual, el relacional y el cognitivo (macro, meso y micro). También han sido fructíferas las tres dimensiones propuestas por Ricoeur ([1989] 2006): la referencialidad (en tanto mediación entre el ser humano y el mundo), la comunicabilidad (entre humano y humano) y la comprensión de sí (el sujeto y sí mismo). 
juego. Cuando l* interrogué sobre cuál fue el momento en el que tomó consciencia de no ser/reconocerse como mujer, me respondió:

[...] no hubo un solo momento, creo que hubieron detonantes más bien, por ejemplo, un detonante, cuando me cambié el nombre, recuerdo mucho que mi intención era, en parte porque me gustaban los nombres pequeños, porque yo quería un nombre que no fuera ni femenino ni masculino [...] El otro, puede ser el tema del corte del cabello [...] era como algo que yo necesitaba vivir y que después de eso empecé como a generar otras posibilidades en mi cuerpo, pero ahí no recuerdo que mi intención fuera no ser mujer sino jugar con el género. (Dan, audio de WhatsApp, 23 de mayo del 2018, énfasis añadido)

Con nuevo corte y ropa "era ya un niño, en ciertos momentos", dado que su corporalidad le permitía esa ambigüedad: "nunca he sido así que tenga un estilo tan masculino, pero tenía ropa que me gustaba y me hacía sentir así” (Dan, entrevista, 10 de septiembre del 2017). Dan descubrió que el cabello es una parte que te construyen de la feminidad, y que, sin buscarlo, había detonado una consciencia sobre otras formas de su cuerpo que no se ajustaban a los imaginarios del género asignado. Así, empezó a experimentar más claramente, a abrirse al juego intuitivo, y cada vez más consciente, con su expresión de género en la cotidianidad. Esta postura, que aparece con mayor acento en la primera entrevista a Dan, se conecta con la apuesta de la activista y artista trans Kate Bornstein, quien argumenta que "el género debería convertirse en un juguete" (Hausman 2001, 473).

En mi caso, desde muy pequeñ* aprendí, gracias a comentarios directos e indirectos, que verse o actuar "masculinamente" era una vergüenza, reprobable, y el asunto de usar determinada ropa fue por largos años una autorrestricción y un tabú. Era evidente mi dificultad con la ropa de la sección "chicas". Duraba horas en la búsqueda de estilos no tan "femeninos" en una avalancha de prendas estereotipadas, porque ir a la de hombres era algo vetado: implicaba evidenciar mi "lesbianismo" y reafirmar el señalamiento común de "querer ser un hombre”.

Mi experimentación con la apariencia ha sido también importante y, al tiempo, he tenido la sensación de estar jugando un juego peligroso. Cuando escuchaba a Dan hablar del disfrute del juego con el género, no podía dejar de pensar por qué yo lo vivía en parte como un asunto lleno de contrariedades, miedo y hasta sufrimiento. ¿Era mi carácter? ¿Me lo tomaba muy en serio? ¿Eran mis experiencias de infancia? Esa actitud de juego ha sido frecuentemente asociada a determinadas subjetividades que transgreden el género asignado en un marco de teatralidad y temporalidad, y se le ha atribuido la fluidez y el goce. Esta forma de asumirlo parece haberse (o estarse) extendiendo también a nuevas 
transgeneridades no binarias. Por mi parte, comprobé en el día a día un movimiento pendular entre la rabia, la indignación y la tristeza, por un lado, y la satisfacción, la picardía y el goce, por el otro, ante miradas de confusión, sorpresa o desprecio. Por ello mi reflexión se acerca a la de Halberstam (2008b), pues concibo la experiencia transgénero masculina (binaria y no binaria) llena de estados, sensaciones y experiencias que mantienen una relación compleja con este tipo de características (fluidez, rigidez, sufrimiento, goce, juego), así como la transexualidad:

[...] estaba intentando hablar de cómo el deseo, el género y la sexualidad suelen ser enormemente rígidos [...] quería cuestionar la creencia en yoes fluidos y también la creencia de que la fluidez y la flexibilidad son siempre y en todas partes deseables [...] muchas, si no todas, las identidades de sexo y género implican cierto grado de movimiento (que no fluye libremente, sino que está muy codificado) entre cuerpos, deseos, transgresiones y acomodaciones. (171)

Por otro lado, Dan comenta que durante esa época hubo otro detonante, al sentir un fuerte desfase con la apariencia "femenina" que se esforzaba por tener durante la indagación que hizo con las mujeres negras del Pacífico nariñense:

Empecé a deconstruir tanto eso de qué era lo femenino que me habían enseñado, que cuando me calvié, que cuando empecé a tener relaciones con las nenas, estaba haciendo el trabajo de grado en Guapi, como allá es todo tan tradicional, como por yo no chocar tanto me llevaba siempre las pintas más femeninas, los vestidos, las faldas, y yo me sentía como disfrazándome de mujer allá [...] porque yo en Cali me vestía de otras maneras que yo sentía que allá no iban a ser tan bien vistas. [...] Les preguntaba por esas cosas y algunas decían: no pues, ya va siendo normal, pero eso es raro, por ahí hay dos. Las que hay allá son súper escondidas, nunca son visibles, y los manes gais pues son la burla del lugar. (Dan, entrevista, 10 de septiembre del 2017)

Cuando habla de lo tradicional, Dan se refiere al rol comunitario de estas mujeres trabajadoras, en su mayoría artesanas tejedoras adultas: el cuidado de la familia y la preparación de alimentos, labores desvalorizadas que buscan reivindicar. Alude también a la relación entre esos roles familiares y comunitarios y la idea de estar determinados biológicamente, presente en este contexto. Ligado a esto se encuentra el peso de la heterosexualidad obligatoria y la aparente imposibilidad del deseo lésbico en las mujeres negras (Cuero 2015; Urrea y Malatesta 2015, 438-439), por lo que sentía que no podía evidenciar su relación con otras mujeres y establece una diferenciación frente al "aspecto femenino" que 
se esforzaba en tener allí. Por otro lado, su mayor aproximación a la interseccionalidad $^{12}$ de las opresiones en esas realidades le permitió identificar las profundas diferencias de su experiencia sociocultural y racial, y percibir que "no hacía parte de esos procesos, ni como mujer ni como persona negra”, sino desde otro lugar, pues el racismo le interpelaba de otras maneras: "el color de piel y otros rasgos que tengo me hacen tener otros privilegios y yo siento que no he pasado ni paso por situaciones por las que personas de un color de piel mucho más oscuro sí pasan" (Dan, audio de WhatsApp, 23 de mayo del 2018) ${ }^{13}$.

Aquella deconstrucción del aspecto femenino que Dan percibía como perturbador en determinados contextos fue continuada en el trabajo corporal a través de la danza y el teatro, en el que afianzó aquellos desprendimientos.

Fue después del proceso de Testosterona [pieza de danza del año 2014] donde empiezo como a ver más claro todo el tema de la masculinidad o mi relación con la masculinidad, yo siento que ya mi búsqueda era ya porque yo ya no lograba identificarme en los grupos de mujeres y por eso yo quería un grupo LGBT, entonces la Fundación llega, otro detonante. (Dan, audio de WhatsApp, 23 de mayo del 2018)

\section{Quiso esa imagen de una princesa: los choques contra el sistema sexo/género}

La experiencia de Martín es diferente a la de Dan porque los roles y la apariencia de "niña" que le querían inculcar con dureza su madre y las instituciones educativas "le chocaban brutalmente", en sus palabras. Esa fuerte contradicción con

12 Este concepto refiere a la imbricación de diversas relaciones de poder y dominación, como clase, raza, etnia, género, edad, situación de discapacidad, y busca la comprensión del papel de estas interdependencias en la configuración de las diferencias y las desigualdades sociales, tanto en el registro de la subjetividad e identidad como en el de las estructuras institucionales más amplias (Crenshaw 1991; Platero 2012; Viveros 2016).

Las personas blanco-mestizas no estamos atadas a las implicaciones de opresión cotidiana del racismo vividas por l*s disidentes sexo/genéric*s negr*s/afrodescendientes e indígenas en su realidad interseccional heredada de las imposiciones coloniales del sistema sexo/género occidental. Se derivan estereotipos sobre estas poblaciones como sin diversidad sexual y el blanqueamiento de lo LBGTQ. Las transmasculinidades blanco/mestizas tienen grandes diferencias frente a las transmasculinidades racializadas, y con seguridad nuestras memorias también. Dan detalla: "me siento la persona más negra de mi familia [...] que me referenciaran siempre con cosas negras eran actos de racismo [...] pero nombrarme de esa manera [persona negra], sentía que era tomar un lugar que desdibuja la lucha que hay detrás, que es una lucha contra el racismo" (Dan, audio de WhatsApp, 22 de noviembre del 2018). 
el género asignado fue vivida en la infancia y preadolescencia, periodo en que se supone debía apropiarse de forma progresiva, pero cada vez más clara y estable, de las características de la feminidad.

Siempre quiso tener esa imagen supermarcada de una princesa, cuando yo se la rompí, y desde muy niño le rompí los güevos. ¿Qué pasó? Ella desde muy niño a mí me daba mucho palo, yo tengo cicatrices en mi espalda. Era que mi mamá me daba muy duro [...] mi mamá me hacía moñas, que un poco de trenzas chimbas y yo me soltaba eso, y niño parce, hasta de cuatro años yo creo, [...] y me hacía solo una hacia atrás, porque claro [...] quedaba con los rasgos más marcados [...]. Tuve muchos problemas porque yo le decía a mi mamá: "mami, hoy toca educación física”, y era mentira, parce. Tenía cinco años [...] yo no quería usar una perra falda, parce. (Martín, entrevista, 24 de mayo del 2018)

Como dice Halberstam (2008a), "la conducta del chicazo ${ }^{14}$ se castiga cuando se convierte en el indicador de una fuerte identificación con el varón [...] y cuando amenaza con prolongarse más allá de la infancia [...] para las chicas la adolescencia es una lección de moderación, castigo y represión” (28). En esta primera visión que nos presenta Martín de su pasado, nos muestra que nunca pudo realizar la plena apropiación interna de los roles y apariencias del género que le fue asignado. La ruptura, más que con una identidad de género incorporada, fue con la imposición de esos parámetros por parte de su madre y del medio social:

Yo siempre pensé que era un niño, hasta quinto de primaria tuve mucho problema porque yo jugaba fútbol, porque a mí me gustaba una niña y yo nunca pensé como que: "ay, yo soy una mujer, no le puedo caer a una niña”; sino que yo fui y yo le dije: "tú me gustas mucho", y fui y le llevé un corazoncito de dulce [tenía nueve años]. ¿Por qué? Porque yo nunca dimensioné el hecho de que yo fuera una mujer [...] yo afuera me veía muy niño, porque yo siempre fui muy niño, entonces yo pensé que era un niño, o sea, que ser niño era eso [...]. Esa niña me denunció en la rectoría, me mandaron a mi mamá, de todo, me mandaron al psicólogo, psiquiatra... fue y dijo: "vea, esa niña me dijo que yo le gustaba”, y yo: “iay, jueputa ${ }^{15}$ ¿ ¿En qué me metí?”. Yo me di cuenta cuando ya todo el mundo me castigó, me regañó, y yo: “marica ${ }^{16}$, yo soy una vieja ${ }^{17}$ y me

Manera española de nombrar a las niñas muy masculinas, utilizada en la traducción al español del libro de Halberstam (2008a). Algunas denominaciones de estas expresiones del género en niñas son marimacho/a o machorra, en ciertos contextos colombianos.

Abreviación coloquial del insulto "hijo de puta".

Expresión coloquial que puede significar gay, pero también se usa para referirse a una persona con quien se tiene confianza, al igual que parce, como sinónimos de amig*, cuate, compañer*.

Una chica o mujer. 
gusta una vieja, pero yo no me veo”. Yo me acuerdo que yo ahí tuve una crisis. (Martín, entrevista, 24 de mayo del 2018, énfasis añadido)

Después de esas dos experiencias ligadas al género, su rechazo de la expresión de género femenina y su gusto por una niña — realidades que no encajaban con "ser mujer"-, aparece en su relato una forma más consciente de no satisfacción con su cuerpo. Esto, junto con su crecimiento y desarrollo biológico, llevan a una fuerte sensación de inconformidad con el cuerpo, que se refleja en el relato de un episodio sucedido unos años más tarde:

A los once mi mamá me pilló en el espejo, con un lápiz de ella pintada una barba y con el pelo pa atrás, y yo estaba llorando en el espejo. Mi mamá me decía que por qué yo lloraba, a mí todavía me gustaba la misma niña. Entonces yo decía: “mamá, es que a mí me gusta Paola y yo siento que ella no me mira, o sea que ella no me ve de esa manera". Mi mamá: "mami, usted es una niña, eso es una etapa, relájese” [...] Ahí fue donde empezó esa vaina que yo me miraba al espejo y yo decía: “mi mamá me dice que yo soy una vieja, pero yo siempre me sentí un man y ahorita, yo sí veo que soy una vieja, pero no me siento vieja”... uy jueputa, y doce años. (Martín, entrevista, 24 de mayo del 2018)

Comparto con Martín esta temprana claridad de no encajar, tanto por la forma de comportarme - vista como sospechosamente masculina-, como por apartarme de la heterosexualidad desde mis más lejanos recuerdos. De manera similar, la relación que tuve con una amiguita fue radicalmente reprendida por su hermano mayor, de quien recibí una agresiva amenaza para alejarme de ella. Yo tampoco había dimensionado que tener un sexo nos limitaba de ese modo: fue la situación relacional la que estableció lo que no podía franquear y que era despreciable. Por años guardé angustiosamente ese secreto que pesaba en mi conciencia infantil, anhelando en las noches despertar siendo un niño. Más tarde este deseo desapareció durante un largo periodo en que intenté apropiarme de la feminidad hegemónica, mientras vivía el crecimiento de mis grandes senos como un sufrimiento. Ya no deseaba ser niño, pero detestaba convertirme en una "mujer”, con los supuestos y las formas de relacionamiento que conllevaba. Hace unos cuatro años me confesaba un intenso deseo por intervenir mis senos: ¿quitarlos o reducirlos?, dilema que permanece incluso después de la cirugía. Reafirmaba también "no soy una mujer” y reaparecía la pregunta sobre el binario: “¿seré (o quiero ser) un hombre?”. Pero, más que una esencia oculta diferente, siento que durante todos estos años he padecido una cantidad de "verdades sociales sobre el sexo/género" que se nos arraigan hasta los tuétanos. Comprender que me aparto también de esa categoría opuesta ha implicado ires y venires. 
En otras partes del relato, la explicación de Martín también señala que su proceso no fue lineal, sino que hicieron falta varios episodios significativos para llegar a la convicción de no ser mujer, al deseo de cambiar su cuerpo y a la decisión de realizar una terapia hormonal. Cuenta que tuvo que vivir etapas superpuestas y no progresivas para entender qué quería. Preguntarse muchas veces "si era un niño o una niña", si gustaba de chicas o chicos, "todo es un camino, o sea, eso es dar tres pasos, devolverse dos, dar otros tres y así...” (Martín, entrevista, 24 de mayo del 2018). Es relevante el vaivén entre estas dos posturas frente a su proceso y cómo la memoria juega estratégicamente hacia una o la otra: cuando aparece un rechazo al género asignado y un proceso de tránsito claro, transparente y lineal, emergen en su relato alusiones al esfuerzo, al trabajo y a la experimentación personal, social y emocional que ese proceso ha implicado para él. Martín me explica que la conciencia más clara y madura de no ser mujer y de la necesidad de cambiar "empezó con mi primera novia”, en el colegio, cuando se sentía "muy niño", pero "explotó” ya en la universidad (Martín, entrevista, 24 de mayo del 2018). Conoció a una amiga y empezaron a frecuentar un grupo de lesbianas hasta que se distanció porque rechazaba que lo consideraran lesbiana:

Esa es de las experiencias que más me han nutrido, porque moverme en el ambiente lésbico me hizo entender que yo no era una lesbiana [...] Entonces, para afuera me tocaba catalogarme como una lesbiana porque no sabía qué era, pero dentro del grupo yo ya decía: "pero marica, es que yo no me siento lesbiana”. (Martín, entrevista, 24 de mayo del 2018)

Aunque Martín comenta que intentó ponerse muy de vez en cuando "uno que otro vestido" y salir con un par de hombres, concluía que "no era lo suyo". Interpreto ese periodo como una búsqueda por apropiarse del género asignado en el marco de la categoría de identidad sexual "lesbiana”, intentos que no dieron fruto en Martín. También es posible entender estos procesos como una diferenciación frente a otras identidades que afianzan la delimitación de lo que se es y no se es.

Por mi parte, si bien la entrada a los círculos lésbicos me permitió desprenderme de creer necesitar ser un hombre, también tuve una gran distancia con la categoría lesbiana. En este proceso de investigación descubrí a Wittig (1992) y me llamó mucho la atención su postura de que la lesbiana no es mujer. Al aproximarme a literatura que enfatiza en la experiencia de machorras (butch $)^{18}$ que rompen con ser mujer y con ser hombre, llegué a pensar que, aunque no me considere

18 Noción en inglés usualmente utilizada para referir a mujeres lesbianas cuya apariencia física o manera de vivir son percibidas socialmente como asociadas al estereotipo de género "masculino". 
así, la experiencia lesbiana ha desempeñado un importante papel en la manera en la que me he ido pensando como persona trans. Dado que no cumplo con la teleología que se le atribuye médicamente a un tránsito de género (reasignación del género opuesto e, idealmente, del sexo), he pensado en reivindicarme como un ser machorr* trans, pues ese insulto que much*s hemos recibido en vivencias cotidianas habla, en últimas, de la transgresión de los parámetros del género que se nos han asignado, y eso para mí hoy es motivo de orgullo.

Martín me explica que adoptó la categoría lesbiana como una designación temporal ${ }^{19}$ pero no necesariamente genuina en su vida:

Fue una etapa rebrutal, yo siempre me consideré muy, muy lesbiana, pues o sea, que solo me gustaban las viejas... como uno solo conoce ese término, uno dice, "bueno, es que yo no me considero lesbiana", pero es el término que uno conoce, lesbiana. Entonces yo decía: "no, a mí solo me gustan las viejas”. (Martín, entrevista, 24 de mayo del 2018)

Martín experimentó varios momentos de consciencia en torno a sus sensaciones de inadecuación y de ruptura con el género asignado que durante años convivieron en compleja relación con distintos momentos de la relación con su cuerpo. En diversas partes de su relato, la memoria que construye tiende a afirmar que la sensación de no pertenecer al género mujer ni a las categorías asociadas con lo femenino (como lesbiana) habitaba en él como una esencia, siempre previa a cualquier situación y acción, como una verdad intuitiva que solo era puesta en evidencia al ser cuestionada por el contexto y las relaciones sociales.

Esta vivencia de lo trans, que experimenta y apela a un origen esencial en el rechazo al género impuesto y concibe el género vivido como una ontología (Hausman 2001; Prosser 1998; Stryker 2006), entra en fuerte contradicción con los postulados de las teorías queer (Butler 2016; Halberstam 2008a; Sedgwick 1998) y feministas desde los cuales el género es, en las primeras, una acción enunciativa así como performática, y en las segundas, una construcción cultural, sociopolítica y económica - no una esencia-. Esta tensión teórica ha sido objeto de polémicas cuyas implicaciones políticas son disímiles y diversas. Al respecto considero pertinente el llamado de Sedgwick (1998) a reformularnos las preguntas en función de su impacto y transformación sobre las desigualdades y

En las subjetividades FTM existen diversas maneras de concebir la relación con la identificación lesbiana en sus vidas. Desde quienes marcan un límite tajante, fijo y atemporal entre la verdad de su género masculino, por un lado, y la identidad lesbiana pasada y momentánea, por otro, manifestando incluso rechazo; o quienes evidencian su identificación temporal como tal, estableciendo fronteras, pero también poderosos vínculos -incluso frecuentando círculos lésbicos después del tránsito- (Deva 1994; Halberstam 2008b). 
las jerarquías vigentes, más que sobre la explicación del origen de la variación sexual y/o de género.

\section{Existe un nombre para esto: no ser mujer, pero ser algo... ser trans}

Otro asunto a destacar en estas dos trayectorias es la búsqueda de información en internet, el descubrimiento de documentos académicos y políticos, y, poco a poco, la conversación con hombres trans. Lo que nos dice Huyssen (2002) acerca de que las memorias nacionales están atravesadas por "los efectos de los medios globales” (21) nos da una pista para analizar cómo la forma en que Dan transita entre los géneros da sentido a su pasado/presente y a su identidad, al tiempo que se configura también mediante múltiples articulaciones con fenómenos globales, como las tecnologías de la información y la difusión de nuevos discursos sobre lo trans y lo queer.

Pero también como que aclaré [con la obra de danza Testosterona] que ser un hombre trans no era lo que quería, no era como dejar de ser mujer para ser hombre [...] veía videos en YouTube, buscaba perfiles [de hombres T] y veía lo que hacían, entonces tuve el interés de aplicarme testosterona [...] pero como estaba empezando una relación, como que sentía ese miedo de cambiar, tenía miedo de vos misme ${ }^{20}$ : ¿quién iba a ser, no? (Dan, entrevista, 10 de septiembre del 2017)

Es tangible la ansiedad de Dan por las posibilidades impensadas e inciertas del futuro del cuerpo, de la identidad y el ser. Al tiempo, nos muestra el proceso de interpretación de su experiencia como un tránsito entre los géneros, a partir de reelaborar otra forma de pensar lo trans, más allá de los estereotipos arraigados en los círculos locales que conocía, transitar al género/sexo opuesto. El acceso a nuevos marcos interpretativos le permitió una problematización del género desde una postura que cuestiona la matriz binaria, echando mano de múltiples (muchas veces contradictorias) ideas que le ayudan a seleccionar y significar el día a día, sus deseos, los cambios y miedos, en función de un presente y un futuro: 
Encontrar cómo nombrar eso de no ser mujer pero ser algo, y fue cuando leí el trabajo de Ana, que habla de las memorias trans [...] porque después de que yo leí eso dije: “¡wow! ¡lo encontré!”. Entonces escribí Transhumano, entonces como que: “iAh! Ya sé lo que soy”. Y después vino el proceso de arte y empoderamiento trans, que ahí era una dualidad porque era un momento en el que estoy hablando de esto porque es algo que yo quiero resolver, aunque no logro identificar si ese trans de lo que estoy hablando soy también yo. Y ya después de eso entonces llega la Escuela Transfeminista y como que ahí ya logro decir: “¡Ya! Existe un nombre para esto, [a] eso que yo vengo sintiendo le puedo dar otra connotación y puedo marcar como ese antes y después”. (Dan, audio de WhatsApp, 23 de mayo del 2018, énfasis añadido)

La dualidad de Dan en el proceso de identificación con la categoría trans habla de cómo se ha construido este referente identitario en el contexto caleño y en la imaginería nacional. Al trabajar en la Fundación y hablar con algunos hombres trans, se encuentra con que las narrativas sobre lo que caracteriza la experiencia trans no coinciden con sus experiencias y anhelos: su punto de llegada no era “el sexo/género opuesto”. A diferencia de la visión teleológica, es decir, la reasignación de género, e idealmente de sexo, Dan reivindica la posibilidad de permanecer en el estado liminal, que es contradictorio en tanto cohabitan aspectos de las distintas estructuras comportamentales en ellas y se "reestructura lo dado por autoevidente" (Castillejo 2017, 8-9). Al tiempo, en su relato se encuentra la clásica producción narrativa y experiencial de la "fractura del tiempo" que dispone un antes y un después, y en la que se fundamenta la idea de tránsito, transición y cambio. En las representaciones tradicionales de los tránsitos, en ese antes se confinan todas las características asociadas al género anterior, para ver nacer casi que una nueva persona con el género y las características opuestas que, a su vez, garantizan el éxito y la coherencia de los dos polos (y estatus). Conversando sobre nuestros tránsitos, coincidimos en percibir una vivencia compleja de continuidades, así como de sensaciones cercanas a aquellos nacimientos, al sentir nuevos registros de experiencia y autopercepción en nuestras subjetividades.

Como veremos más adelante, las presiones para que se confinen determinadas características en el pasado (lo visto socialmente como femenino) están de manera palpable en los contextos en los que Dan se mueve, como condición para ser percibid* de una manera distinta. Por todo lo anterior, considero que lo que vivimos en los tránsitos - binarios o no- es precisamente una dialéctica entre 
transformaciones y permanencias, entre antes y después (Castillejo 2017) ${ }^{21}$, más allá de las ideas de ruptura total-nacimiento o mera continuidad. Esta dialéctica se configura de manera significativa y diferente según la mediación de fuerzas y estructuras sociales, imaginarios y prácticas de género que circulan en nuestros contextos, poderes enraizados en las subjetividades e instituciones, así como por la potencia desestructurante de la liminalidad y la agencia de las personas trans.

Por otro lado, en la memoria personal y comunicativa de Dan sobre su elaboración identitaria como una persona trans no binari*, convergen acontecimientos relevantes para la memoria colectiva y la historia de las personas trans a nivel nacional, como la Escuela Transfeminista desarrollada por Mujeres al Borde en Bogotá en el 2017. Todo esto nutrió su lectura sobre sí mism* y le permitió acceder y anclarse a un marco interpretativo emergente que también disputa la transformación de esos marcos sociales del recuerdo objetivados en los dispositivos hombre/mujer. Como señala Riaño-Alcalá (2006), "las prácticas de recuerdo y olvido están mediadas social y culturalmente; en consecuencia, nuestros actos de memoria afirman o niegan algo en relación con nuestros procesos de construcción de identidad” (XLIV). En este caso, la mediación social de la memoria individual se da a través de redes organizativas trans y queer nacionales que constituyen un proceso histórico que aún está por ser contado.

El reconocimiento de lo trans aparece en dos momentos distintos de las entrevistas con Dan. El primero en el $2012^{22}$, durante el Primer Encuentro Lesbitransinterfeminista Venir al Sur realizado en Paraguay, donde conoció chicos y chicas trans. Alude a estos recuerdos enfatizando que hoy parecen significativos a pesar de que en aquella época no fueron relevantes para interpelar su propia identidad. El momento posterior es su llegada a la Fundación y su búsqueda activa de información sobre las hormonas y la existencia de otro tipo de tránsitos.

Después de este proceso de consciencia y reelaboración personal, en la entrevista del 2017 y en coherencia con el sentido dado hasta ese momento a su identidad, Dan consideraba que su intención no era reafirmar cada vez más un aspecto totalmente masculino, llegar a tener barba y asumir los estereotipos de lo que es ser "un hombre de verdad" en nuestros contextos. Al mismo tiempo, tenía otra sensación: ya era claro que no se identificaba como mujer, había

21 Ha sido fructífero analizar los tránsitos como estados de liminalidad, procesos de transformación ritual — "ritos de paso"- y la experiencia del tiempo social que implica desde el enfoque de Castillejo (2017). Propongo apropiar este marco como analogía, sin equiparar las complejidades de fenómenos diferentes, ni los contenidos específicos vinculados a las transiciones políticas y sociales que ese autor analiza. 
reflexionado sobre aspectos de su cuerpo que hacían que socialmente $\mathrm{l}^{*}$ vieran como tal y quería cambiarlos para adquirir un aspecto menos femenino,

Cuando hablaba era lo que más me feminizaba, porque yo comencé a percibir que a veces mi estética podía hacer dudar a las personas: "ay, es un hombre, es una mujer", no sabes, pero apenas hablaba ya como que quedaba claro que para las personas era leíde como una mujer [...]

Uno de ellos [chico trans] habló de que lo primero que le cambió cuando se aplicó testosterona fue la voz [...] que ese cambio era irreversible, y cuando yo escuché eso fue como que dejé de sentir el miedo, como que reafirmé algo que yo quería. (Dan, audios de WhatsApp, 23 de mayo del 2018)

La reflexión de Dan nos habla de la conexión entre los niveles cognitivo, relacional y contextual (Tilly 2001) —o la mediación social de las decisiones individuales-, al mostrarnos cómo una decisión o acción individual de transformación corporal se toma en el marco de procesos sociales que promueven las redes organizativas, formales e informales, para poner a circular determinadas prácticas y marcos interpretativos (como la Escuela Transfeminista, la red de organizaciones y activistas que sustentan estos espacios), y que constituyen procesos sociales mucho más amplios y contextuales. También alude al papel de lo relacional, al resaltar la interacción cara a cara como una dimensión que genera una permanente interpelación del género, así como posibilidades de acceso a información preciada sobre las experiencias de otras personas en tránsitos.

En agosto del 2017 Dan me propuso iniciar nuestra terapia de reemplazo hormonal, que mantuvimos durante seis meses, en su caso, y tres meses, en el mío. En febrero del 2018 la suspendió, debido a la situación económica derivada de su mudanza de país, y en razón de haber priorizado su reflexión sobre los cambios experimentados, intentando vivirlos sin "presionarme con el tema del trabajo, mientras vivo en mi cuerpo y resuelvo esa nueva imagen que tengo de mí” (Dan, audio de WhatsApp, 22 de noviembre del 2018). Durante esa época prefirió no averiguar el precio de las hormonas porque vivir al día no le permitía ningún gasto adicional, al tiempo, me contó que estaba en un proceso de indagación y exploración personal para saber si era capaz de vivir con un cuerpo lleno de pelos y barba: “yo sé que si continúo con hormonas, eso es lo que se viene”. Mi percepción del ejercicio de Dan era ambivalente, consideré que lo hacía no solo para saber si le gustaría o lo soportaría, sino que se esforzaba por acostumbrarse, transformando su visión sobre estas características corporales al proyectarse en el presente y el futuro con ellas - se pintaba barbas en las fotos de sus perfiles, entre otras prácticas visuales y corporales-. 
Durante la segunda entrevista en marzo de ese mismo año, Dan manifestó que se siente más cómod* con que l* llamen con pronombres masculinos cuando las personas no logran utilizar el neutro para referirl*, siente mayor molestia con los apelativos femeninos ${ }^{23}$. Se ha dado cuenta de que, si quiere que no se le asuma como mujer, los parámetros de la masculinidad le presionan para abandonar determinadas formas de llevar y recodificar el cuerpo. Su postura inicial, acentuadamente individualista y queer ${ }^{24}$, que le permitía asumir que "lo que eres solo está determinado por tu interior, sin depender de las miradas de l*s otr*s", hoy convive con lecturas más centradas en las contradicciones entre su anhelo por no ser tomad* como mujer y las formas rígidas de la masculinidad que se le exigen, si quiere lograrlo. Entre su autopercepción y la de la mirada ajena; entre la sensación que le invade insistentemente de no haber cambiado corporalmente lo suficiente, frente a las transformaciones cada vez más radicales que se proyectan en sus futuros posibles y la imagen que tiene de su propia identidad no binaria, la libre elección parece no ser tan fácil; la sociedad observa y demanda.

En nuestra última conversación por Skype, Dan comentó algo que ya me había dicho algunas veces: la relación que tiene con su pasado es de "borramiento", expresado en su vida de varias maneras. Una de ellas, me explica, fue su decisión de vender y regalar todo, incluyendo gran parte de su ropa, antes de migrar. En esa época Dan vivía en mi casa, por lo que hablamos varias veces de que no quería llevar nada de su pasado, que quería iniciar un nuevo ciclo en el que la gente le vería tal como quería y no como le habían conocido o interpretado antes. En una de nuestras videollamadas informales en agosto del 2018, mientras hablamos sobre un corto documental que realicé acerca de mis propias memorias del tránsito personal (Déjà vu), Dan me explicó que le llamaba la atención la manera como me relaciono con mi pasado y que justamente estaba trabajando para incorporar imágenes y elementos de su pasado en su nueva performance. Me comentó que lo ve como una manera de reflexionar sobre algo que simplemente omite, pues más que dolor parece experimentar extrañeza y una ausencia de interés por eso que llama "su pasado": "como una culpa [...] como si el pasado

23 Cambiar de pronombres ha sido difícil no solo para Dan, sino para mí, y al parecer incluso para quienes tienen claro su pronombre deseado. Es también una problematización el pronombre para hablar de nosotr*s en el pasado, much*s usamos el de la identidad actual, pero algún*s lo variamos según con quien hablemos. con la política blanca liberal de igualdad de derechos LGBT y la diversidad de debates sobre sus aportes, me refiero aquí a lo que algun*s le atribuyen: una noción neoliberal del individuo que supone su capacidad para actuar de manera desregulada sin barreras, "al promover un sujeto autónomo guiado únicamente por el relativismo" (López 2018, 255), lo que dificulta las acciones colectivas. 
fuera una cosa de: 'no, pero vos no eras eso' [...] como si fuera mentira”' (Dan, conversación, 5 de noviembre del 2018).

Dan no quiere volver ni visitar Colombia en un futuro cercano, hasta que tenga mayores claridades sobre cómo se quiere ver y cómo se siente en cuanto al proceso de los tránsitos múltiples. Un viaje que fue soñado y planeado buen tiempo antes de iniciar conscientemente su tránsito adquiere un propósito que se torna mucho más relevante que las otras razones que le motivaron antes: distanciarse de sus contextos para poder ser otras cosas, y esto pasa también por cambiar de oficios, actividades y proyecciones a futuro. Es significativo que un plan cultivado por más de dos años, como el de migrar a Brasil, fuese activado al mismo tiempo en que decidió iniciar su terapia hormonal y terminar su relación amorosa. En este nuevo contexto ha encontrado círculos y personas que le permitieron ir definiendo algunos sentidos más complejos de lo que venía siendo su autodenominación:

[...] he seguido pensando en eso que te había dicho de la no binariedad, si es una identidad o no, porque a veces lo siento como si uno no fuera nada, [...] la palabra trans tiene un poco más de significado y amplitud y permite generar más diálogos [...] creo que la mayoría de personas que transitan pasan por experiencias no binarias que nos permiten construir nuestra propia corporalidad, nuestra propia identidad, he pensado mucho eso en estos días que conozco a otras personas que se nombran de otras maneras [varias bixas ${ }^{25} \mathrm{y}$ un hombre trans] pero que yo les leo desde una óptica no binaria, y digo, sus experiencias pasan por las reflexiones que yo me hago, solo que no lo llaman de esa manera. (Dan, audio de WhatsApp, 7 de noviembre del 2018) ${ }^{26}$

Por otro lado, Martín es muy claro al enfatizar que, si bien él "no se sentía vieja”, la dificultad de no conocer la posibilidad de ser un hombre trans pesaba mucho, como una especie de limbo: "pero, entonces qué es esto, porque llega un punto donde, digamos a los quince años, yo no sabía el tema ni nada de lo que

Dan me explica que en Brasil es una manera coloquial de referirse a hombre homosexual con una expresión muy femenina o afeminados. Usado por "algunas travestis" o en conversaciones informales para decir "amig", "compañer*". Una connotación cercana a marica en Colombia.

26 Interesante paralelo con la reflexión del artista FTM Jordy Jones sobre las fronteras entre experiencias: "Jones cuestionaba la idea misma de que la experiencia transexual pudiera ser representada de una forma universal y totalizadora: no todo el que experimenta disforia de género lo hace de la misma manera, y no todos lo gestionan igual. No todas las personas transgénero toman hormonas, y no todo el que toma hormonas es transgénero. Yo tengo un amigo (genéticamente mujer) que se identifica como hombre y que pasa como tal perfectamente. Nunca se ha inyectado nada. Y sin duda conozco bolleras (lesbianas) que son más butch de lo que yo lo seré en mi vida, pero que nunca pensarían en identificarse en otra cosa más que como mujeres" (Halberstam 2008b, 173). 
es ser trans” (Martín, entrevista, 24 de mayo del 2018). Recuerda haber hecho conciencia de la posibilidad de serlo más o menos a sus dieciocho años, en su reencuentro con una de las personas del grupo de lesbianas, que había hecho su proceso de transformación corporal y ahora tenía como nombre Juan:

Lo volví a ver en un Petronio ${ }^{27}$ [entre 2010 y 2011] [...] ya a él le estaba saliendo barba, y yo: “marica, vos qué hiciste”, [amigo:] "no, parce, es que yo me alejé por esto, esto y esto”, y yo: “ijuepuuta! ¡Eso se puede hacer!”, me decía: “claro, eso es tal, tal y tal”, y yo: “jueputa, yo no lo puedo creer” [...] Claro, porque yo pensé que uno tenía que vivir en su cárcel de su cuerpo toda la vida, o sea, yo lo pensé porque yo no sabía nada, no tenía personas que me comunicaran nada [...] hasta le metí como un morbo, pero un morbo de investigar mucho [...] le conté a mi mejor amiga: “parce, Juan se volvió trans”, y ella: “sí ¿y qué?”, y yo: “pues yo no sé, yo siento que ese es mi camino” [...] [amiga:] "noo, marica, dejá la bobada que no pasa nada, vos sos una vieja”. Lo dejé morir por un tiempo hasta que, parce, uno ya la, o sea, a uno ya la cabeza no le da más y uno cuando se siente de otra manera diferente a como se ve, es diferente, y ya me empezó a obsesionar. (Martín, entrevista, 24 de mayo del 2018)

En el 2013 no toleró más un fuerte cuestionamiento interno y se agudizó la profunda molestia de que lo vieran como mujer, pero ahora sabía que era posible intervenir su cuerpo, "hasta que putié una señora en una panadería, esa señora no tenía nada que ver" - por decirle "niña”- "Me fui llorando de esa panadería”. Con ese episodio, Martín comenzó a buscar decididamente la manera de transformar su cuerpo:

Empecé a averiguar, duré casi un año intentando conseguir hombres trans aquí en Cali [...] empecé a investigar en páginas, a leer, como sabía de la existencia de Juan, empecé a buscar sus fotos, a buscar si había reportes [...]. Fue muy difícil de comunicar, supe que había un amigo de Juan, trans, el man de una me dijo: "no, parce, usted es una lesbiana confundida” [...]. Ya cuando me vieron [Juan] en un grupo como de Chile o México, averiguando en internet, o sea, en Facebook, sobre cómo hacer un proceso de tránsito [...] ahí sí como que: “ve, parce, ¿verdad que vos sos trans?”. Y yo: “idios mío! Yo no sé, pero yo me estoy sintiendo como un man, y estoy necesitando apoyo y nadie me lo da”. (Martín, entrevista, 24 de mayo del 2018)

A partir de los relatos de Martín y de Dan vemos que el vínculo con algunas organizaciones y personas trans es ambivalente; no siempre son un apoyo para

27 Hace referencia al Festival de Música del Pacífico Petronio Álvarez que se realiza todos los años en la ciudad de Cali desde hace 23 años. [N. de la e.] 
el desarrollo de seguridad y confianza en el propio proceso de tránsito. En sus narrativas hay referencias a estereotipos de género tradicionales o de lo trans, algo que también percibí al participar en algunos espacios trans de Cali. Al tiempo que en las organizaciones trans, feministas o institucionales circulan informaciones necesarias que aportan para que vivamos un tránsito más tranquilo, también se promueven visiones del género y de los tránsitos que restringen esas posibilidades. Como cuenta Martín sobre su experiencia en uno de los primeros grupos de hombres trans de la ciudad de Cali:

Aun así el grupo de manes trans no me ayudó para nada, antes de empezar hormonas y después de empezar hormonas. A mí esos encuentros, por el contrario, me devolvieron por completo mentalmente [...] porque hay masculinidades muy marcadas que, si vos no estás en esa idea de masculinidad, vos sos un marica, o seguís siendo una lesbiana, así quieras hormonas, seguís siendo una lesbiana o un marica. (Martín, entrevista, 24 de mayo del 2018)

Ante esto Martín retomó su reflexión en torno a su incomodidad con el término lesbiana, pero esta vez para argumentar que si bien considera que no se sintió como una, él como hombre trans no puede pordebajiar el término ni negar que

[...] todos tenemos que empezar de una manera y si nos tenemos que catalogar de una manera, todos fuimos lesbianas, [...] todos hemos tenido que pasar por la etapa de habernos tenido, al menos que ver, no sentir, pero que ver como una lesbiana. (Martín, entrevista, 24 de mayo del 2018)

Su reflexión insiste en lo siguiente: con frecuencia es codificado socialmente como un hombre afeminado y delicado. Esto no solo a lo largo de la entrevista sino en nuestros encuentros informales como amig*s, ya que es común que hablemos de cómo nos ve la gente. Frases como: "yo para correr soy muy gay”, "yo como de manera muy delicada” y su apreciación de ser pretendido eróticamente por chicos gais forman parte de una consciencia sobre cómo es visto por mucha gente. Martín evidencia un giro hacia una postura diferente frente a la presencia de aspectos muy femeninos en su manera de vestirse y de llevar el cuerpo cuando se sintió exhausto de esforzarse en actuar como un chico rudo para contrarrestar su aspecto tierno, su gestualidad y sus gustos comúnmente catalogados por otros hombres trans como afeminados:

Tuve que llorar, tuve que de todo para decir: “ieh, marica! Yo no me tengo que dejar crecer los perros pelos pa' decir que soy un hombre”. Porque yo decía: “¿será que entonces realmente yo no soy un man?”. Porque es que ellos me están diciendo que ser un man es esto, esto y esto y pa mí, iyo no soy así! (Martín, entrevista, 24 de mayo del 2018) 
En contrapartida, en su relato vemos como un referente muy importante el impacto de un joven trans de Bogotá “que le ayudó como un putas” en su tránsito, gracias a las reflexiones y consejos que le proporcionó. Riki le explicó que, gracias a las luchas de las mujeres y a su empoderamiento, ellas habían reivindicado diversas formas de ser mujer, pero que los hombres seguían anclados a una sola manera y “iles encanta esa chimbada!”. Reunidos en la casa de Juan, Riki le dijo:

Yo a usted lo veo encartado con el tema [del tránsito], usted no intente encajar en algo, si usted se siente hombre, bien, es más, ni siquiera se catalogue, si se siente así está bien, pero no piense en esas imágenes sino que haga lo que a usted lo hace feliz. (Martín, entrevista, 24 de mayo del 2018)

Esto se lo dijo para que no le pasara lo mismo que a él, que se esforzó por encajar en ideas de hombre y no vivió como quería durante un periodo de su tránsito. Le dijo que veía que “estaba pasándolo mal”, adoptando gestos y gustos que no le hacían bien. Martín me expresó con entusiasmo: "a mí me cambió tanto la percepción que yo digo, a mí este man me salvó de un abismo que no se imagina” (Martín, entrevista, 24 de mayo de 2018). Le describió con elementos masculinos y femeninos a la vez (barba y labios pintados, pantalones aladinos o faldas); después de seis años de hormonarse, concluyó que no encajaba en ser un hombre.

En el relato de Martín se evidencia la tensión frente al modelo de "la verdadera masculinidad”, que demarca quiénes son realmente hombres. Surgen preguntas que también retumban en el contexto de visibilización de las subjetividades FTM, donde se caldea la disputa por la futura configuración de esas identidades transmasculinas diversas: "las guerras de los límites entre las butches transgénero y los FTM presuponen que la masculinidad es un recurso limitado, disponible solo para unos pocos y en cantidades que se van agotando cada vez más” (Halberstam 2008b, 168). La rivalidad entre FTM, transmasculinidades no binarias y masculinidades femeninas está a la orden del día en esta encrucijada por determinar quién es y quién no, y, como vimos, también entre los mismos hombres trans. Estas disputas hacen parte de los elementos que condicionan y median nuestras memorias, en tanto estructuran, acreditan o desacreditan nuestras identidades.

Las estrategias de estas dos personas para apelar a determinados elementos de su pasado, significar su presente y elaborar su identidad les permiten enfrentar las fracturas simbólicas, íntimas y sociales que implica el tránsito entre los géneros en esta sociedad, así como delimitar las nociones, fronteras y diferencias con otras categorías y experiencias. El reconocimiento de esos elementos codificados como contradictorios supone un esfuerzo psicológico, emocional y 
conceptual que se apoya en diversas redes de sentido. Incorporar a tu presente esa identidad que buscas transformar y que al mismo tiempo te define... que revalúas, pero que simultáneamente te habita —en las fotografías, en las múltiples formas del pasado, en aspectos de tu cuerpo, en tus historiales clínicos y jurídicos, en los imaginarios que la familia, $\mathrm{l}^{*} \mathrm{~s}$ amig*s y conocid*s tienen de ti-, es un reto en este mundo binario.

Y dicen [sus conocid*s]: “¡ah! ¡Cambiaste!... pero no tanto... seguís siendo vos...” y uno en su búsqueda de no seguir siendo eso que las otras personas ven. Ahí es cuando digo: “¡no has entendido nada!”. Y digo: “¿hasta dónde tendré que llegar para que las personas perciban que es un cambio?...”. Igual tengo mucho cuidado con esa pregunta porque yo no estoy cambiando por las otras personas, ¿sí? Es como esa tensión siempre entre lo que vos sentís y lo que las otras personas esperarían de vos, y esto no solo se da en los tránsitos binarios, sino también en lo queer ${ }^{28}$. (Dan, entrevista, 21 de mayo del 2018, énfasis añadido)

En ese tiempo yo también [decía]: "jueputa, odio a esa vieja, esa vieja es una porquería y tal”. Pero yo te digo, parce, o sea, ahorita no, desde hace mucho tiempo yo digo: "a mí me construyó todo lo que fue, la lucha que hizo Martha”. [...] Mi esposa nunca ha olvidado a Martha y ella me dice: “yo nunca olvidaré, ni dejaré de querer, ni dejaré de extrañar a Martha”, para mí es algo que hizo parte de mí, que me marcó mucho. [...] A veces no sé cómo interpretar eso, si es que yo me considero dos personas que al final se unieron en una, yo por dentro siempre fui Martín y por fuera siempre fui Martha, pero quien tuvo las vivencias no fue Martín, porque nunca pudo salir a pesar de todo; quien salió y puso la cara y le tocó llorar y todo fue a Martha. [...] Le tocó sufrir el lomo y que mi mamá le pegara... cortarse el pelo a la mala. Martín estaba adentro esperando, nunca estuvo ausente, pero a quien le tocó comer mierda al principio fue a Martha, [...] [eso hizo] que Martín saliera y se juntaran, porque para mí afortunadamente Martha nunca se murió, eso fue una fusión muy brutal, porque pa mí se juntaron los dos como tenía que ser, es que nos formamos dos, que estaban uno afuera y uno adentro, y eso se formó de una manera que yo digo, eso es lo que me hace ser lo que yo soy. (Martín, entrevista, 24 de mayo del 2018)

28 En este y otros puntos de la entrevista, Dan se refiere a los imaginarios sobre lo que debe caracterizar a una persona queer. Estos imaginarios circulan en determinadas redes de personas que se enuncian queer, frecuentadas por Dan y que, en su opinión, también establecen estéticas y estereotipos determinados. 


\section{Consideraciones finales}

Para deconstruir la necesidad de pasar ${ }^{29}$, las transexuales deben responsabilizarse de toda su historia, empezar a rearticular sus vidas no como una serie de borraduras (tachaduras). Stone ([1992] 2015, 61)

Hablar de las memorias de mis compañer*s implica mostrar su esfuerzo por hacer inteligible una experiencia que es incoherente desde la matriz occidental cultural del género como marco social de memoria cultural y colectiva. Dicha matriz produce el género y encuadra los cuerpos en dos polos excluyentes, exigiendo (de muy diversas maneras) borrar la mezcla de estos en las vidas, las memorias y los cuerpos trans (Stone 2015). Los marcos interpretativos que han explicado el fenómeno trans lo han ubicado principalmente en el plano de lo patológico, por lo que interpretar una historia personal implica una disputa interna en diálogo con las historias que han sido contadas sobre nosotr*s por las autoridades médico-jurídicas y/o religiosas dominantes.

Sin embargo, nuevas perspectivas circulan hoy en redes organizativas en las que se construyen y apropian variadas formas de reinterpretarnos. Dos de los grandes paradigmas sobre las identidades y experiencias trans, el modelo médico-psiquiátrico y la teoría queer, han llevado a la "teorización homogénea de las identidades transgénero” (Martínez-Guzmán y Montenegro 2009, 4). Si bien las nutren, como vimos en sus relatos, estos paradigmas "se diluyen en un intrincado laberinto de intereses políticos, estrategias de supervivencia y adaptación social, negociaciones y reconfiguraciones” (4). Apropiamos de manera desigual, yuxtapuesta y contradictoria distintos discursos que nos permiten - 0 no-rescatar aquellos aspectos del pasado que son leídos socialmente como algo discontinuo e incoherente de cara a la identidad presente, es decir, evidenciarlos o borrarlos del relato. Se plasma así la complejidad de la producción del pasado y de la ilusión de continuidad identitaria en las subjetividades trans, pues se desajustan del statu quo. Comprender estos procesos de subjetivación tiene profundas consecuencias en la concepción y teorización de lo trans.

Dan y Martín muestran ese ejercicio de selección del pasado, al producir una memoria que posibilita una identidad trans - y viceversa- diferenciada en distintos planos de las masculinidades hegemónicas y del registro globalizado de

\footnotetext{
29 "Pasar es lo mismo que borrar el rol de género anterior o la construcción de una historia plausible" (Stone 2015, 58) y también "hace referencia al hecho de que una persona trans pase desapercibida en el género en el que se identifica" (Galofre y Missé 2015a, 22).
} 
la patologización. Simultáneamente, sus relatos muestran las dificultades derivadas de la estructura binaria del género que median sus decisiones y recuerdos, en "un forcejeo constante que permite, por un lado, circular por los espacios públicos normalizados por la concepción dominante de sexo/género y, por el otro, generar líneas de fuga que inauguran y visibilizan espacios habitables fuera de la lógica binaria” (Martínez-Guzmán y Montenegro 2009, 32).

La reflexión de Martín sobre su vínculo con la categoría lesbiana muestra esa tensión entre presencia y borramiento, en un movimiento de reconciliación y distanciamiento, así como el rencor hacia Martha y la decisión de recuperarla. Aunque ya no esté físicamente, Martha "nunca se ha muerto", me dice, evidenciando la materialización de una corporalidad, una apariencia social y una autodenominación masculinas. Su necesidad de transformación corporal es vista por Martín en términos de que "su cuerpo era una cárcel”, una de las narrativas más comunes desde la década de los cincuenta en Occidente para describir los cuerpos trans, asociada con los discursos médicos y autobiográficos de personas transexuales (Halberstam 2008b; Missé 2018, 23-40; Stryker 2017), vinculándolos con una esencia que se encuentra encerrada en un cuerpo equivocado.

En su relato, Martín integra la existencia de un ser que parece otro, pero que fue él mismo, trayendo esa representación femenina que la visión hegemónica de la masculinidad se esfuerza por extirpar a la definición actual de su identidad, reivindicándola como un pasado-presente. A partir de ese vínculo ambivalente, elabora su autoimagen como un hombre en gran medida forjado por las experiencias y vivencias de Martha. De esta manera, cuenta una versión alternativa de la historia del género en un tránsito, en un esfuerzo por no silenciar un gran periodo de su existencia. La identidad y la forma en que Martín ve su tránsito implican una simultaneidad de seres pasados y presentes. Tanto en Martín como en Dan conviven formas de percibir y construir el tiempo de manera lineal, junto con un registro que niega esa progresividad. El tránsito es aquí una experiencia personal y social del tiempo.

Dan también manifiesta una relación problemática con su pasado, puesto que, aunque se esfuerza por abrazar la ambigüedad y resignificar los códigos de lo que se supone femenino y masculino, suspendiendo tales categorías, experimenta un anhelo por dejar atrás y fuera de la vista aquello que otras personas han percibido antes en elle, por ejemplo, lo materializado en sus viejas fotografías. La progresividad del tiempo en su relato aparece junto a la percepción de atemporalidad: el pasado es borrado para que un presente absoluto proteja la identidad a validar.

Las expectativas y la necesidad del cambio de un estatus inicial de género hacia otro estatus estimulan la producción de una frontera diseñada para 
confinar en un antes las características y formas de relacionamiento social impuestas. Entendida como un estado difuso, la liminalidad desata poderosas presiones al poner en entredicho la dicotomía de género. De ahí también el esfuerzo por generar la ruptura en el continuo temporal y en aquellas características. Sin embargo, se hace necesario reconocer el tránsito como una relación dialéctica entre transformación y permanencia, mediada por fuerzas ligadas a estructuras sociales, imaginarios y prácticas en circulación.

Para Dan, una mayor masculinización corporal aparece por momentos como la salida a una situación recurrente, en la cual es socialmente percibid* y tratad* en femenino, asunto que marca sus futuros posibles. Paralelo a esto, la retrospectiva elaborada por Dan se distancia radicalmente de las ideas sobre el cuerpo equivocado e incorpora sin ambigüedad su experiencia como mujer, al reconocer ese lugar como uno que habitó, al igual que recupera su identificación como lesbiana, alejándose de la autonarración de alguien que nunca fue mujer.

Lo anterior nos muestra que las maneras en que experimentamos los pasados, presentes y futuros son configuradas también por conexiones significativas con categorías que se han establecido como diferentes en nuestros relatos (mujer - asignada al nacer-, lesbiana —explorada-). Nos explicamos a nosotr*s mism*s describiendo y dando sentido a experiencias de las que nos diferenciamos así como a representaciones y prácticas asociadas a ser lesbianas, gais o trans en nuestros círculos; nos rememoramos con otr*s, trazando fronteras, porosas o abismales.

Se abre una interesante discusión sobre las relaciones entre distintas transgeneridades (binarias y no binarias), así como sobre las experiencias transexuales y su paradigma médico canónico. Halberstam (2008b) controvierte la idea popular del continuum de masculinidad, el cual asume que una diversidad de transgeneridades masculinas y de masculinidades femeninas se dirige inevitablemente hacia la transexualidad masculina como transexuales no definidos. Por el contrario, aboga por reconocer un lugar existencial, epistemológico y cultural a l*s "butch transgénero" 30 de su contexto, independiente del paradigma de la transexualidad. Considero útil extrapolar esta reflexión, no la etiqueta butch, para cuestionarnos el lugar de las personas transmasculinas que no nos enunciamos como hombres. Se hace necesario comprender nuestras experiencias sin

30 Halberstam denomina de esa manera la intersección entre transgeneridad y masculinidad femenina lesbiana, al apropiar la noción popular estadounidense butch y adicionarle transgénero para hacer énfasis en la identidad y prácticas transgénero de masculinización que adoptan. Se ha considerado, más que como una inversión simétrica o copia de la masculinidad de hombres cis, como subjetividades que develan el carácter social (o ficcional) de esa masculinidad hegemónica (Halberstam 2008; Lacombe 2006; Romero y Platero 2012, 170). 
que se nos asuma como una etapa preliminar, sea para ser "verdaderamente mujeres" o "verdaderamente hombres”. Urge señalar que las posibilidades de este lugar propio existencial, epistemológico y cultural dependen muchas veces de las presiones que el contexto social ejerce sobre las subjetividades y las memorias de estas personas.

Por ello, la manera en que Martín se cuestiona a sí mismo y a los modelos de masculinidad legítimos de sus pares repercute también en las transmasculinidades no binarias. Está en juego la posibilidad de ser hombres apartándose de determinados parámetros, de vivir formas distintas de corporalidad, representación y relacionamiento, sin ser castigados con violencia simbólica o física, ni con barreras que impiden el acceso a derechos. De reestructurar los marcos con los que pensamos el cuerpo, el género y la sexualidad depende la posibilidad de desactivar el continuum de violencia que afecta a parte de la población LTBG de la sociedad colombiana. Otras memorias posibles implican nuevas maneras de vivir y transgredir el género, maneras menos angustiosas; y trastornar las formas de rememorarnos es abrir la puerta a este cambio.

\section{Referencias}

Aguilar Fernández, Paloma. 2008. “Acerca de la memoria del aprendizaje y el olvido”. En Políticas de la memoria y memorias de la política. El caso español en perspectiva comparada, 29-93. Madrid: Alianza.

Assmann, Jan y John Czaplicka. 1995. “Collective Memory and Cultural Identity”. New German Critique 65: 125-133. DOI: 10.2307/488538

Balzer, Carsten. 2010. “Eu acho transexual é aquele que disse: 'eu sou transexual!'. Reflexiones etnológicas sobre la medicalización globalizada de las identidades trans a través del ejemplo de Brasil”. En Missé y Coll-Planas 2010, 81-96.

Benjamin, Harry. (1966) 1999. The Transexual Phenomenon. Nueva York: The Julian Press.

Bourdieu, Pierre. 1989. "La ilusión biográfica”. Historia y Fuente Oral 2: 27-33. https://www. jstor.org/stable/27753247?seq=1/subjects

—. 2002. "La objetivación participante”. Apuntes de Investigación 10: 87-101.

Butler, Judith. 2016. El género en disputa. El feminismo y la subversión de la identidad. Barcelona: Paidós.

Cabral, Mauro. (2006) 2011. “La paradoja transgénero”. En Sexualidad, ciudadaníay derechos humanos en América Latina. Un quinquenio de aportes regionales al debate y la reflexión, editado por Carlos F. Cáceres, María Esther Mogollón, Griselda Pérez-Luna y Fernando Olivos, 97-104. Lima: IESSDEH, UPCH. http://www.iessdeh.org/usuario/ftp/integrado1.pdf 
—. 2009. “Asterisco”. En Interdicciones, editado por Mauro Cabral, 14. Córdoba: Anarrés. https://brujulaintersexual.files.wordpress.com/2016/07/interdicciones2.pdf

Calveiro, Pilar. 2012. "Apuntes sobre la tensión entre violencia y ética en la construcción de las memorias políticas”. En Topografías conflictivas. Memorias, espacios y ciudad en disputa, editado por Valeria Durán y Anne Huffschmid. Buenos Aires: Nueva Trilce. http:// www.cels.org.ar/common/documentos/Calveiro.pdf

Castillejo, Alejandro. 2017. La ilusión de la justicia transicional: perspectivas críticas desde el sur global. Bogotá: Ediciones Uniandes.

CIDH (Comisión Interamericana de Derechos Humanos). 2015. "Violencia contra personas lesbianas, gay, bisexuales, trans e intersex en América”. Consultado el 30 de julio del 2019. http://www.oas.org/es/cidh/informes/pdfs/ViolenciaPersonasLGBTI.pdf

CNMH (Centro Nacional de Memoria Histórica). 2013. ¡Basta Ya! Colombia: memoria de guerray dignidad. Resumen ejecutivo. Bogotá: $\mathrm{CNMH}$.

-. 2015. Aniquilar la diferencia. Lesbianas, gays, bisexuales y transgeneristas en el marco del conflicto armado colombiano. Bogotá: CNMH; Uariv; Usaid; OIM.

—. 2018. Un carnaval de resistencia. Memorias del reinado trans del río Tuluni. Bogotá: CNMH, USAID. http://www.centrodememoriahistorica.gov.co/informes/publicaciones-por-ano/2018/ un-carnaval-de-resistencia-memorias-del-reinado-trans-del-rio-tuluni

Collins, Patricia Hill. 1998. "La política del pensamiento feminista negro”. En ¿Qué son los estudios de mujeres?, compilado por Marysa Navarro y Catharine Stimpson, 253-312. Buenos Aires: Fondo de Cultura Económica.

Colombia Diversa, Caribe Afirmativo y Santamaría Fundación. 2015. “Cuerpos excluidos, rostros de impunidad. Informe de violencia hacia personas LGBT en Colombia”. Consultado el 30 de julio del 2019. http://colombiadiversa.org/ddhh-lgbt/Informe-Violencia-LGBTColombia-DDHH-2015.pdf

Crenshaw, Kimberlé. 1991. "Beyond Racism and Misogyny: Black Feminism and 2 Life Crew”. Boston Review 16 (6): 6-30. http://bostonreview.net/archives/BR16.6/crenshaw.html

Cuero, Astrid. 2015. “¿Quién desea a las mujeres negras?: la vivencia de las mujeres negras heterosexuales”. En Feminidades y sexualidades: mujeres negras, indígenas, blancas-mestizas y transgeneristas negras en el suroccidente colombiano, editado por Fernando Urrea y Jeanny Posso, 317-428. Cali: Fondo Editorial de la Universidad del Valle.

Deva. 1994. "FTM/Female-to-Male: An Iterview with Mike, Eric, Billy, Sky, and Shadow”. En Dagger: On Butch Women, editado por Lily Burana y Linnea Due, 67-154. Pittsburgh, San Francisco: Cleiss Press.

Feinberg, Leslie. (1992) 2015. "Liberación transgénero: un movimiento cuyo tiempo ha llegado”. En Galofre y Missé 2015b, 67-103.

Galofre, Pol y Miquel Missé. 2015a. Introducción a Galofre y Missé 2015b, 19-29.

—, eds. 2015b. Políticas trans. Una antología de textos desde los estudios trans norteamericanos. Madrid: Egales. 
García Becerra, Andrea. 2009. “Tacones, siliconas, hormonas y otras críticas al sistema sexo-género. Feminismos y experiencias de transexuales y travestis”. Revista Colombiana de Antropología 45 (1): 119-146. https://www.redalyc.org/articulo.oa?id=105012398005

Ghasarian, Christian. 2008. "Por los caminos de la etnografía reflexiva”. En De la etnografía a la antropología reflexiva: nuevos campos, nuevas prácticas, nuevas apuestas, dirigido por Adolfo Colombres, 9-42. Buenos Aires: Del Sol.

Gillis, John. 1994. “Memory and Identity: The History of a Relationship”. En Commemorations. The Politics of National Identity, editado por John Gillis, 3-24. Princeton: Princeton University Press.

Goffman, Erving. (1974) 2006. Frame Analyiss. Los marcos de la experiencia. Madrid: Siglo XXI.

Halberstam, Judith. 2008a. Masculinidad femenina. Madrid: Egales.

—. 2008b. "Butch transgénero. Las guerras del límite Butch/FTM y el continuum masculino". En Masculinidad femenina, 165-199. Madrid: Egales.

Halbwachs, Maurice. (1968) 2004. La memoria colectiva. Zaragoza: Prensa Universitaria de Zaragoza.

Hall, Stuart. 2010. "La cuestión de la identidad cultural”. En Sin garantías. Trayectorias y problemáticas en estudios culturales, compilado por Eduardo Restrepo, Catherine Walsh y Víctor Vich, 363-404. Popayán: Envión.

Haraway, Donna. (1988) 1995. “Conocimientos situados: la cuestión científica en el feminismo y el privilegio de la perspectiva parcial”. En Ciencia, cyborgs y mujeres. La invención de la naturaleza, 313-346. Madrid: Cátedra.

Harding, Sandra. 2003. "Rethinking Standpoint Epistemology: What Is "Strong Objectivity?”. En The Feminist Standpoint. Theory Reader. Intellectual \& Political Controversies, editado por Sandra Harding, 127-140. Nueva York: Routledge.

Hausman, Bernice L. 2001. "Recent Transgender Theory”. Feminist Studies 27 (2): 465-490. DOI: $10.2307 / 3178770$

Huyssen, Andreas. 2002. En busca del futuro perdido. Cultura y memoria en tiempos de globalización. Ciudad de México: Fondo de Cultura Económica.

Kessler, Suzanne y Wendy MacKenna. 1978. Gender: An Ethnomethodological Approach. Chicago: University of Chicago Press.

La Furcia, Ange. 2016. "Los colores de las fantasías. Estudios sobre masculinidades en Colombia: crítica feminista y geopolítica del conocimiento en la matriz colonial”. Revista Colombiana de Sociología 39 (1): 47-78. https://revistas.unal.edu.co/index.php/recs/article/ view/56341

Liberarte. 2018. "La OMS reconoce que la transexualidad no es una enfermedad mental”. Consultado el 18 de septiembre del 2018. https://www.liberarte.co/es/recursos/ articulos/260-la-oms-reconoce-que-la-transexualidad-no-es-una-enfermedad-mental

Losada, Camilo. 2016. "Pedagogías decoloniales y cocuidado: un aporte en la reconstrucción y restitución de la memoria colectiva de hombres transgénero de la organización social Hombres en Desorden”. Tesis de Licenciatura en Educación Comunitaria con Énfasis en Derechos Humanos, Facultad de Educación, Universidad Pedagógica Nacional, Bogotá. 
Martínez-Guzmán, Antar y Marisela Montenegro. 2009. "Narrativas en torno al trastorno de identidad sexual. De la multiplicidad transgénero a la producción de trans-conocimientos”. Prisma Social Revista de Ciencias Sociales 4: 1-44. http://www.isdfundacion.org/publicaciones/revista/pdf/03_N4_PrismaSocial_antar_marisela.pdf

Missé, Miquel. 2018. A la conquista del cuerpo equivocado. Madrid: Egales.

Missé, Miquel y Gerard Coll-Planas, eds. 2010. El género desordenado. Críticas en torno a la patologización de la transexualidad. Barcelona: Egales.

Ortiz Gómez, Ana María. 2014. “Tránsitos como experiencia e identificación. Análisis de las experiencias trans localizadas en cuerpos asignados mujeres en Bogotá desde la perspectiva biográfica y feminista”. Tesis de Maestría en Estudios de Género, Facultad de Ciencias Humanas, Universidad Nacional de Colombia, Bogotá.

Platero, Raquel Lucas. 2012. "La interseccionalidad como herramienta de estudio de la sexualidad”. En Platero 2012b, 15-74.

—, ed. 2012b. Intersecciones: cuerpos y sexualidades en la encrucijada. Temas contemporáneos. Barcelona: Bellaterra.

Posso, Jeanny y Angie La Furcia. 2016. "El fantasma de la puta-peluquera: género, trabajo y estilistas trans en Cali y San Andrés Isla, Colombia”. Revista Latinoamericana Sexualidad, Salud y Sociedad 24: 172-214. https://www.e-publicacoes.uerj.br/index.php/SexualidadSa ludySociedad/article/view/20899

Prosser, Jay. 1998. Second Skins: The Body Narratives of Transsexuality. Nueva York: Columbia University Press.

Ramírez, Ana L. 2015. "Memorias fuera del género: cuerpos, placeres y políticas para narrarse trans”. Tesis de Maestría en Estudios de Género y Cultura, Mención Humanidades, Universidad de Chile, Santiago de Chile.

Riaño-Alcalá, Pilar. 2006. Jóvenes, memoria y violencia en Medellín: una antropología del recuerdo y el olvido. Medellín: Universidad de Antioquia.

Ricoeur, Paul. (1989) 2006. "La vida: un relato en busca de narrador”. Ágora: Papeles de Filosofía 25 (2): 9-22. https://minerva.usc.es/xmlui/bitstream/handle/10347/1316/;jsessionid=C 3AAC7D2CFAEF93E81E70D1367D42BFC?sequence=1

-. 2007. "Historia y memoria. La escritura de la historia y la representación del pasado". En Historizar el pasado vivo en América Latina, dirigido por Anne Pérotin-Dumon, 3-27. Santiago de Chile: Centro de Ética-Universidad Alberto Hurtado. http://www.historizarelpasadovivo.cl/downloads/ricoeur.pdf

Romero Bachiller, Carmen y Raquel Lucas Platero. 2012. "Diálogos interseccionales sobre lo Butch/femme, las diásporas queer y lo trans”. En Platero 2012b, 159-198.

Sánchez, Gonzalo. 2016. "La memoria, una aliada para la paz”. Revista Conmemora 4: 4-5. http://www.centrodememoriahistorica.gov.co/noticias/noticias-cmh/revista-conmemora-edicion-especial-la-memoria-una-aliada-para-la-paz

Saldivia Menajovski, Laura. 2017. Subordinaciones invertidas: sobre el derecho a la identidad de género. Los Polvorines; Ciudad de México: Universidad Nacional de General Sarmiento; Universidad Nacional Autónoma de México. 
Scott, Joan. 1996. "El género, una categoría útil para el análisis histórico”. En El género. La construcción de la diferencia sexual, compilado por Marta Lamas, 265-302. Ciudad de México: PUEG.

Sedgwick Kosofsky, Eve. 1998. Epistemología del armario. Barcelona: Ediciones de la Tempestad.

Serano, Julia. 2007. Whipping Girl. A Transsexual Woman on Sexism and The Scapegoating of Femininity. Nueva York: Seal Press.

Stone, Sandy. (1992) 2015. “El imperio contraataca. Un manifiesto postransexual”. En Galofre y Missé 2015b, 31-65.

Stryker, Susan. 2006. “(De)Subjugated Knowledges: An Introduction to Transgender Studies”. En The Transgender Studies Reader, editado por Susan Stryker y Stephen Wittle, 1-17. Nueva York: Routledge.

—. 2015. Prólogo a Galofre y Missé 2015b, 9-18.

-. 2017. Historia de lo trans. Madrid: Continta Me Tienes.

Suess, Aimar. 2010. "Análisis del panorama discursivo alrededor de la despatologización trans: procesos de transformación de los marcos interpretativos en diferentes campos sociales”. En Missé y Coll-Planas 2010, 29-54.

Tilly, Charles. 2001. "Mechanisms in Political Processes”. Annual Review of Political Science 4: 21-41.

Urrea, Fernando y Consuelo Malatesta. 2015. "Placer y afecto: mujeres negras lesbianas y bisexuales”. En Feminidades y sexualidades: mujeres negras, indígenas, blancas-mestizas y transgeneristas negras en el suroccidente colombiano, editado por Fernando Urrea y Jeanny Posso, 429-469. Cali: Fondo Editorial de la Universidad del Valle.

Viveros, Mara. 2016. "La interseccionalidad: una aproximación situada a la dominación”. Debate Feminista 52: 1-17. http://www.debatefeminista.cieg.unam.mx/wp-content/ uploads/2016/12/articulos/052_completo.pdf

Wacquant, Loïc. 2006. Prólogo a Entre las cuerdas. Cuadernos de un aprendiz de boxeador, por Loïc Wacquant, 21-28. Buenos Aires: Siglo XXI.

Winter, Jay. 2008. "Historical Remembrance in the Twenty-First Century". The Annals of the American Academy of Political and Social Science (617): 6-13. https://www.jstor.org/sta ble/25098009

Wittig, Monique. 1992. El pensamiento heterosexual y otros ensayos. Madrid: Egales.

Wittle, Stephen. 2006. Prólogo a The Transgender Studies Reader, editado por Susan Stryker y Stephen Wittle, XI-XV. Nueva York: Routledge. 